\title{
Merit Aid, College Quality and College Completion: Massachusetts' Adams Scholarship as an In-Kind Subsidy.
}

\section{Citation}

Cohodes, Sarah, and Joshua Goodman. Merit Aid, College Quality and College Completion: Massachusetts' Adams Scholarship as an In-Kind Subsidy. American Economic Journal: Applied Economics, 2014.

\section{Published Version}

10.1257/app.6.4.251

\section{Permanent link}

http://nrs.harvard.edu/urn-3:HUL.InstRepos:33370070

\section{Terms of Use}

This article was downloaded from Harvard University's DASH repository, and is made available under the terms and conditions applicable to Open Access Policy Articles, as set forth at http:// nrs.harvard.edu/urn-3:HUL.InstRepos:dash.current.terms-of-use\#OAP

\section{Share Your Story}

The Harvard community has made this article openly available.

Please share how this access benefits you. Submit a story.

\section{Accessibility}




\title{
Merit Aid, College Quality and College Completion: Massachusetts' Adams Scholarship as an In-Kind Subsidy*
}

\author{
Sarah Cohodes \\ Harvard University \\ cohodes@fas.harvard.edu \\ Joshua Goodman ${ }^{\dagger}$ \\ Harvard University \\ Joshua_Goodman@hks.harvard.edu
}

January 31, 2014

\begin{abstract}
We analyze a Massachusetts merit aid program that gives high-scoring students tuition waivers at in-state public colleges with lower graduation rates than available alternative colleges. A regression discontinuity design comparing students just above and below the eligibility threshold finds that students are remarkably willing to forgo college quality and that scholarship use actually lowered college completion rates. These results suggest that college quality affects college completion rates. The theoretical prediction that in-kind subsidies of public institutions can reduce consumption of the subsidized good is shown to be empirically important.
\end{abstract}

*For making the data available for this project, we are indebted to Carrie Conaway, Director of Planning, Research and Evaluation, and Robert Lee, MCAS Chief Analyst, both at the Massachusetts Department of Elementary and Secondary Education, as well as Jon Fullerton, Executive Director of the Center for Education Policy Research at Harvard University. We also thank for helpful comments Chris Avery, David Deming, Sue Dynarski, David Figlio, Ed Glaeser, Sandy Jencks, Tom Kane, Kevin Lang, Jeff Liebman, Bridget Long, Dick Murnane and Marty West, as well as seminar participants at Harvard, MIT, Boston University, NBER, the Federal Reserve Banks of Boston and New York, APPAM, AEFP and SOLE. Institutional support from the Harvard Kennedy School of Government and Taubman Center for State and Local Government are gratefully acknowledged. Any errors are our own.

${ }^{\dagger}$ Corresponding author. 


\section{Introduction}

Recent research has emphasized troubling trends in U.S. college completion rates over the past few decades. Among students entering college, completion rates are lower today than they were in the 1970s, due largely to low completion rates of men and students from lower socioeconomic backgrounds (Belley and Lochner 2007, Bailey and Dynarski|2011). This trend has spurred a vigorous debate over the relative importance of factors that vary across students, such as academic skill and family financial resources, and factors that vary across postsecondary institutions, such as funding levels or management quality. Distinguishing the influence of student-level and institution-level factors on college completion rates is confounded by the non-random selection of students into institutions of different apparent quality. In this paper, we provide further evidence consistent with the fact that the quality of the institutions themselves affects college completion rates.

To do so, we exploit is a Massachusetts merit aid program in which high school students with test scores above multiple thresholds were granted tuition waivers at in-state public colleges. Such colleges were of lower quality than the average alternative available to such students, where quality is measured by a combination of graduation rates, academic skill of the student body, and instructional expenditures, as suggested by Black and Smith (2006). The scholarship, though relatively small in monetary value, induced substantial changes in college choice, allowing us to estimate the impact of college quality on students' postsecondary enrollment decisions and rates of degree completion. A regression discontinuity design comparing students just above and below the eligibility threshold finds that students are remarkably willing to forgo college quality for relatively little money and that marginal students lowered their college completion rates by using the scholarship. College completion rates decreased only for those subsets of students forgoing the opportunity to attend higher quality colleges when accepting the scholarship. We describe the magnitude of this response as remarkable because the value of the scholarship is dwarfed by estimates of the forgone earnings of attending a lower quality college or failing to graduate. As a whole, these results suggest that college quality has a substantial impact on college completion rates. We also find clear evidence that this scholarship increased college enrollment, though not graduation, rates for the most disadvantaged students. Such students comprise, however, an 
extremely small fraction of the total pool of those eligible for this merit aid.

Our research contributes to three strands in the literature on postsecondary education and the public subsidy of such education. First, a now extensive literature documents the sensitivity of students' college enrollment decisions to financial aid generally (Deming and Dynarski|2010, Kane 2006) and merit aid more specifically (Dynarski 2000, Cornwell et al. 2009, Dynarski 2008, Kane 2007. Pallais 2009. Goodman 2008 [1. In contrast to most of the programs studied in this literature, the Adams Scholarship targets a very highly skilled set of students, namely the top $25 \%$ of high school graduates in each school district. As a result, our estimates are generated by a part of the skill distribution not often studied. Furthermore, unlike in most aid programs, recipients were automatically notified of their eligibility without having to apply. Simplifying the aid process is known to affect students' college enrollment decisions (Bettinger et al. 2012), so that this program design may explain in part the large impacts of aid observed here. Our results are also consistent with Fitzpatrick and Jones (2012), which finds that merit aid does effectively keep some students in state but that marginal students are a small fraction of total aid recipients.

Second, we add to the growing literature on the impact of college quality on student outcomes. Much of the literature on the impact of college quality on degree completion has focused on the community college sector, reaching varying conclusions about whether access to and quality of community colleges affects educational attainment (Rouse 1995, Leigh and Gill 2003, Sandy et al. 2006. Calcagno et al. 2008, Stange 2009, Reynolds 2012). Estimates of the impact of college quality on labor market earnings are similarly varied, with some positive (Loury and Garman 1995. Brewer et al.|1999, Chevalier and Conlon 2003, Black and Smith|2004, Black and Smith|2006, Long 2008. Hoekstra 2009, Andrews et al. 2012), some zero or positive only for disadvantaged subgroups (Dale and Krueger 2002, Dale and Krueger 2011), and some suggesting that earnings differences dissipate once the job market properly understands graduates' underlying ability (Brand \begin{tabular}{|l|}
\hline \hline${ }^{1}$ This paper represents an extension and improvement of \\
\hline gram at an earlier time and used less informative outcome data. In particular, that earlier paper could only measure \\
\hline whether graduating high school seniors self-reported their intention to enroll in public or private colleges, without \\
\hline identification of specific campuses, actual enrollment or persistence and graduation. This paper, in contrast, uses sub- \\
\hline stantially more detailed administrative data that allows identification of the specific institutions students actually enroll \\
\hline in, as well measurement of persistence and graduation rates. This allows for clear estimation of the quality and cost \\
\hline tradeoffs students are making, the impact of this merit aid on in-state enrollment and, perhaps most importantly, the \\
\hline impact of this aid on college graduation rates. \\
\hline
\end{tabular} 
and Halaby 2006, Lang and Siniver 2011). Nearly all of these research designs attempt to eliminate selection bias either by conditioning on students' observable characteristics or by instrumenting college quality with distance from or tuition of nearby colleges. Neither approach entirely eliminates the possibility that unobserved student-level factors may be driving their estimates. The exception to this is Hoekstra (2009), which uses a discontinuity inherent in the admissions process to a flagship university to estimate the labor market return to an elite college education. We employ a similarly identification strategy and unlike Hoekstra are able to observe the college choice made by students not enrolling in the target institutions, allowing us to estimate the impact of merit aid on college quality. Though sources of exogenous variation in school and curriculum quality are more common at lower levels of schooling because of school choice lotteries (Deming et al.2011) and test score-based admissions rules (Bui et al. 2011, Abdulkadiroglu et al. 2011, Dobbie and Fryer 2011), they are rarer in the postsecondary literature.

Furthermore, our finding that college quality plays an important role in completion rates is consistent with important pieces of recent evidence. Controlling for rich sets of student characteristics does not eliminate wide variation among postsecondary institutions in completion rates (Bowen et al. 2009). Students who attend college in large cohorts within states have relatively low college completion rates, likely stemming from decreased resources per student given states' tendencies to change public postsecondary budgets slowly (Bound and Turner 2007). Bound et al. (2010) argue that the vast majority of the decline in completion rates can be statistically explained by decreasing resources per student within institutions over time and, even more importantly, shifts in enrollment toward the relatively poorly funded public sector. All of this suggests that characteristics of colleges themselves, such as resources available per student, play an important role in completion rates and that student-level factors are only part of the story.

Third, we show the empirical importance of the theoretical possibility first discussed in Peltzman (1973) that in-kind subsidies of public institutions can reduce consumption of the subsidized good. Prior work has shown how public in-kind subsidies can generate at least partial crowdout of privately provided health insurance (Cutler and Gruber 1996, Brown and Finkelstein 2008), preschools (Bassok et al. 2012) and two-year colleges (Cellini 2009). Peltzman's contribution was 
the prediction that, in some cases, crowdout could theoretically be large enough to reduce overall consumption of the subsidized good. Work by Ganderton (1992), using cross-state variation in tuition subsidies, and Long (2004), using much finer college-specific variation in such subsidies, suggests that this in-kind public support for postsecondary education does reduce overall spending on education. We contribute to this literature by providing the first evidence of such reduced consumption driven by an exogenous shock in the size of the in-kind subsidy. We also show that this reduced spending on higher education comes at the cost of a reduced probability of degree completion, a possibility recognized by Kane (2007) in his evaluation of the D.C. Tuition Assistance Grant program but unexplored because too little time had passed to look beyond enrollment effects.

The structure of the paper is as follows. In section 2, we describe the merit scholarship program in detail. In section 3, we describe the data on students and colleges, including our measures of college quality. In section 4, we explain our empirical strategy, a regression discontinuity design that accounts for the multiple thresholds students must cross in order to be eligible for aid. In section 5, we present estimates of the impact of college quality on enrollment decisions and completion rates. In section 6, we discuss implications of our findings and conclude in section 7.

\section{The Adams Scholarship}

All Massachusetts public high school 10th graders take the Massachusetts Comprehensive Assessment System (MCAS), which includes an English language arts (ELA) portion and a mathematics portion. Scores on each portion range in multiples of two from 200 to 280, with 260-280 categorized as "advanced" and 240-258 as "proficient". In January 2004, Massachusetts Governor Mitt Romney proposed the John and Abigail Adams Scholarship Program, which would waive tuition at in-state public colleges for any student whose total MCAS score placed him or her in the top $25 \%$ of students statewide $2^{2}$ Romney's two stated goals seemed to be keeping highly talented

\footnotetext{
${ }^{2}$ The eponymous couple cared deeply about education. John Adams wrote, in the Massachusetts Constitution, that "Wisdom, and knowledge, as well as virtue... as these depend on spreading the opportunities and advantages of education in the various parts of the country, and among the different orders of the people, it shall be the duty of legislatures and magistrates, in all future periods of this commonwealth, to cherish the interests of literature and the sciences, and all seminaries of them; especially the university at Cambridge, public schools and grammar schools in
} 
students in state and improving the quality of the state's public postsecondary institutions. In his January 15, 2004 State of the Commonwealth speech to the Massachusetts legislature, Governor Romney explained that "I want our best and brightest to stay right here in Massachusetts.' ${ }^{3}$ Conversations with individuals involved with the scholarship's inception also suggest that Massachusetts wanted the recently introduced MCAS exam to be seen as a valid measure of student achievement and was thus willing to, in effect, put its money where its mouth was.

Concerned that Governor Romney's statewide standard would assign scholarships largely to students in wealthy, high-performing school districts, the state Board of Higher Education ultimately approved a modified version of the program in October $20044^{4}$ Under the approved policy, which has continued through at least 2013, a student receives a tuition waiver if his or her MCAS scores fulfill three criteria. First, he or she must score advanced on one portion of the exam. Second, he or she must score proficient or advanced on the other portion of the exam. Third, the student's total MCAS score must fall in the top $25 \%$ of scores in his or her school district $5^{5}$ The scores used to determine eligibility come from each student's first attempt at taking the grade 10 MCAS tests in ELA and mathematics. To receive the scholarship, a student must be enrolled in and graduate from a Massachusetts public high school in his or her senior year. The graduating class of 2005 was the first to receive Adams scholarships.

Scholarship winners are automatically notified by letter in the fall of their senior year. The scholarship waives tuition at any of four University of Massachusetts (U. Mass.) campuses, nine (four-year) state colleges, or fifteen (two-year) community colleges $]^{6}$ As such, the letter that Governor Romney sent to the first class of scholarship recipients promised in bold-faced and underlined letters "four years of free tuition." Receipt of the scholarship does not, however, eliminate the cost

the towns" (Chapter V, Section II). Abigail Adams, disturbed by the 18th century gender gap, wrote that "It is really mortifying, sir, when a woman possessed of a common share of understanding considers the difference of education between the male and female sex, even in those families where education is attended to" (Letter to John Thaxter, February 15, 1778). sell.

${ }^{3}$ See the January 20, 2004 Boston Globe article, "Specialists Blast Romney Proposal for Free Tuition," by Jenna Rus-

${ }^{4}$ See the October 20, 2004 Boston Globe article, “New MCAS Scholarship OK'd," by Jenna Russell.

${ }^{5}$ As of the class of 2006, students in charter schools or who participate in school choice or the Metco program can fulfill the third criterion by placing in the top $25 \%$ of the district they attend or the district in which they reside.

${ }^{6}$ Six of Massachusetts' state colleges (Salem, Bridgewater, Fitchburg, Framingham, Westfield and Worcester) were renamed "state universities" in 2010. For simplicity, we refer to them as "state colleges" throughout the paper. 
of college attendance. To clarify the distinction between tuition and fees, the letter to the second class of scholarship recipients added to its final paragraph the disclaimer that "College fees and rooming costs are not included in this scholarship award." More recent letters have emphasized this fact even more clearly $]^{7}$

Figure A.4 shows the tuition and mandatory fees at the University of Massachusetts at Amherst and Bridgewater State College, the two largest campuses in their respective sectors. Strikingly, at both campuses and nearly all other public Massachusetts colleges, tuition has remained constant in nominal terms over the past decade. Mandatory fees have, however, risen dramatically $[8$ For the first class of scholarship winners in 2005, the tuition waiver was worth $\$ 1,714$ annually if used at U. Mass. Amherst or $\$ 910$ if used at Bridgewater State. Given mandatory fees of $\$ 7,566$ at U. Mass. Amherst and \$4,596 at Bridgewater State, the Adams Scholarship thus represented a roughly 20\% reduction in the direct cost of attendance. By the fall of 2011, fees had risen by more than a third, so that the Adams Scholarship represented a less than 15\% reduction in the cost of attendance. These percentages would be substantially lower if room, board and other expenses were included in the total cost of attendance. Conversations with individual colleges' financial aid offices also suggest that for some students this aid is factored into financial aid offers and may be partially crowded out as a result $?^{9}$ The Adams Scholarship thus lowers the cost of college attendance by well under $20 \%$, may be partially crowded out by college financial aid offices, is worth at most $\$ 6,856(4 * \$ 1,714)$ over four years, and is substantially less valuable than other well-known merit aid scholarships such as the Georgia HOPE and CalGrant awards (Dynarski|2008, Kane|2007). By all of these measures, the Adams Scholarship represents a relatively small amount of financial aid.

\footnotetext{
${ }^{7}$ See Figures A.1, A.2 and A.3 for copies of these letters.

${ }^{8}$ This peculiar detail may be due to the fact that tuitions are set by the Massachusetts Board of Higher Education and flow directly to the state's General Fund, while fees are set by each college's Board of Trustees and are retained by the colleges themselves.

${ }^{9}$ We spoke to financial aid officers at all of the U. Mass. campuses about their current policies, which they all believed have been in place since the inception of the Adams Scholarship. All four ask students to send their notification letters as soon as possible in the admissions process, as the financial aid offices do not have their own list of winners. U. Mass. Amherst said there was little scope for crowdout because most students send their letters after receiving financial aid offers, though students who send the letters early may be offered grant money in place of a tuition waiver. U. Mass. Lowell said that scholarship status was used in determining financial aid offers and that late notification of scholarship eligibility results in a recalculation of the aid offer. U. Mass. Boston and Dartmouth also said that scholarship status was used in determining financial aid offers but claimed that scholarship winners who would otherwise have qualified for tuition waivers would instead receive other funding.
} 
Finally, those eligible for the scholarship can use it for a maximum of eight fall and spring semesters only if they graduate from a Massachusetts public high school, are accepted at a Massachusetts public college or university, and enroll at that institution full-time by the fall following their high school graduation 10 The student must also complete the Free Application for Federal Student Aid (FAFSA) and send the Adams Scholarship award letter to the financial aid or bursars office at the institution he or she plans to attend ${ }^{11}$ To continue receiving the Adams Scholarship, a student must continue his or her full-time enrollment at a Massachusetts public college or university, must maintain a cumulative college GPA of at least 3.0, and must complete the FAFSA annually.

\section{Data, Descriptive Statistics and College Quality}

\subsection{Data and Descriptive Statistics}

The Massachusetts Department of Elementary and Secondary Education (DESE) provided the data, which include demographic information, test scores, and Adams Scholarship status for all Massachusetts public high school students expected to graduate from high school from 2004-2011. We use first time 10th grade MCAS test scores. In both math and ELA, we observe scaled scores that determine scholarship eligibility, as well as the raw scores on which those scaled scores are based. We use two main analysis samples, high school graduates from the classes of 2005-06, for whom we observe six-year college graduation rates, and high school graduates from the classes of 2005-08, for whom we observe four-year college graduation rates 12

College outcomes come from DESE's merge of its data on high school graduates with the National Student Clearinghouse (NSC) database, which covers $94 \%$ of undergraduates in Mas-

\footnotetext{
${ }^{10}$ The most recent cohorts are allowed to use the scholarship within six years of graduating high school, but such cohorts are not included in our analysis.

${ }^{11}$ Scholarship users must also be a U.S. citizen or permanent resident of the U.S. and must have been a permanent legal resident of Massachusetts for at least one year prior to entering college as a freshman.

${ }^{12}$ We limit the sample to high school graduates, as only graduates were ultimately eligible for the Adams scholarship. Of those who receive the Adams scholarship letter in the fall of 12th grade, over $98 \%$ ultimately graduate from high school. We find no evidence that receipt of this letter affected high school graduation rates, so this restriction does not create selection bias.
} 
sachusetts ${ }_{13}^{13}$ We observe for each high school graduate every detailed college enrollment spell through 2012 and graduation if it occurs ${ }^{14}$ We add to this additional characteristics such as college costs and quality measures from the U.S. Department of Education's Integrated Postsecondary Education Data System (IPEDS) and the 2009 Barron's rankings of colleges. We separate colleges into Adams eligible institutions (U. Mass. campuses, state colleges and community colleges) and other institutions, such as in-state private or out-of-state colleges.

Table 1 shows the mean characteristics of the two analysis samples. Columns 1-3 contain the classes of 2005-06 and columns 4-6 contain the classes of 2005-08. Column 1 contains the full sample, column 2 limits the sample to students eligible for the Adams Scholarship, and column 3 limits the sample to those within a certain distance of the eligibility threshold, as will be described below. Panel A shows that Adams eligible students are half as likely than the average high school graduate to be low income, black or Hispanic, because these characteristics are all negatively associated with the test scores determining eligibility. Panel B shows that $25 \%$ of high school graduates are eligible for the scholarship and that those eligible score about one standard deviation higher on their MCAS exams than the average high school graduate.

Panel C shows that 79\% of Adams eligible students enroll full-time in a four-year college by the fall following their high school graduation, which we refer to as immediate enrollment. Of these, one third (26\%) enroll in in-state, public, four-year colleges (Adams colleges). Panels D and E show that only 54\% graduate from a four-year college within four years of high school graduation but that $71 \%$ have graduated by their sixth year. Statistics for the sample comprising the classes of 2005-08 look quite similar. Comparison of the graduation statistics to the enrollment statistics across college sectors in these samples suggest that Adams colleges have substantially lower graduation rates than do the in-state private and out-of-state colleges.

\footnotetext{
${ }^{13}$ This figure comes from comparing NSC enrollment numbers to those contained in IPEDS. The remaining $6 \%$ come largely from for-profit institutions and those whose highest degrees take less than two years to complete. Such institutions tend to enroll students with relatively low academic skill, so that the overall match rate for those eligible for the Adams Scholarship is likely even higher than $94 \%$. Coverage is slightly lower in the Northeast as a whole, with $90 \%$ of undergraduate enrollment covered by the NSC. Again, excluded colleges are mainly technical institutions.

${ }^{14}$ We exclude part-time enrollment spells and those less than 60 days long, though this has little effect on our results.
} 


\subsection{College Quality}

Figure 1 confirms this difference between college sectors, plotting by initial enrollment sector the fraction of students graduating within a certain number of years. We generate these figures using NSC's data on four-year college enrollers from Massachusetts' high school class of 2004, prior to the existence of the Adams Scholarship. About $40 \%$ of those who enroll in U. Mass. campuses graduate within four years. The comparable figure for Massachusetts state colleges is well under $30 \%$. For in-state private colleges and out-of-state colleges, that figure is about $60 \%$. A large fraction of students in in-state public colleges use a fifth or even a sixth year to graduate. Even so, six (and even seven) years out of high school there exist large gaps in the graduation rates between these sectors. This evidence makes clear that Massachusetts' public four-year colleges have substantially longer times to degree completion and lower ultimate completion rates than the alternative colleges available to Massachusetts students.

To explore why these sectors differ so dramatically in their on-time completion rates, Table 2 provides a more detailed description of the college market facing Massachusetts students. Quality and cost measures reported by IPEDS in the fall of 2004 are weighted by enrollment of Massachusetts students and thus represent the average student's experience of that sector. In panel A, IPEDS' measure of four-year completion rates tells a very similar story to NSC's measure, namely that U. Mass. campuses and state colleges have far lower on-time graduation rates than do nonAdams colleges ${ }^{15}$ Some part of this variation may be due to the academic skill of incoming students. Students enrolling in state colleges have much lower SAT scores than those enrolling in other sectors, although the U. Mass. campuses look fairly similar to non-Adams colleges in this regard. Non-Adams colleges also spend an annual average of nearly $\$ 15,000$ per student on instruction, nearly twice the spending of U. Mass. campuses and more than three times the spending of state colleges. This resource gap may reduce students' access to coursework or to academic support necessary to complete such coursework and may thus help explain some of the completion rate gap. Relative to their competitors, Massachusetts' public colleges thus have sub-

\footnotetext{
${ }^{15}$ Note that IPEDS measures the completion rate of all undergraduates in these institutions, whereas Figure 1 measures the completion rate only of students coming from Massachusetts public high schools.
} 
stantially lower graduation rates, attract students of somewhat lower academic achievement and spend much less money on instruction.

Whether differences in graduation rates between these sectors are due to differences in incoming student achievement, resources available for instruction or other factors is beyond the scope of the paper. We follow Black and Smith (2006), who argue that because each such of these variables measures college quality with error, relationships between them and outcomes of interest will be biased toward zero. We adopt their suggestion to measure college quality by combining information from multiple variables in order to reduce such measurement error. Specifically, we construct college quality from our student-level data as the first component from a principal component analysis of each college's four-year graduation rate, SAT math 75th percentile of incoming freshmen, and instructional expenditures per student, all of which are measured by IPEDS as of 2004, prior to the Adams Scholarship. We think of the first variable as capturing the ultimate outcome of interest, the second as capturing a measure of student quality and the third as capturing a measure of available resources $\sqrt{16}$ The first principal component from this analysis captures $64 \%$ of the variation between these three variables and nearly equally weights all three. We standardize this quality measure to have mean zero and standard deviation one.

The final row of panel A shows that, by this measure of college quality, U. Mass. campuses and state colleges are 0.32 and 0.94 standard deviations lower than the average quality college attended by Massachusetts high school graduates. Non-Adams colleges are 0.29 standard deviations higher in quality. It is important to note here that this measure of quality is not necessarily a measure of how effectively the various college sectors are using their available resources. Though the Adams colleges have lower graduation rates and instructional expenditures, these facts may be explained in part by the fact that those colleges have much less funding per student. Panel B shows that the total cost of U. Mass. campuses and state colleges, including fees, room, board and books, are $\$ 15,000$ and $\$ 11,000$ respectively. This is about half of the $\$ 29,000$ sticker cost of their competitors ${ }^{17}$

\footnotetext{
${ }^{16}$ Black and Smith construct their quality measure using a slightly broader set of variables. We find that all of these quality measures are so highly correlated that it makes little difference whether we include more than three of them.

${ }^{17}$ In-state community colleges, at which the scholarship could also be used, are essentially open admissions campuses. In fall 2004, they charged on average $\$ 831$ in tuition, $\$ 2,073$ in fees, and $\$ 5,797$ in other expenses, so that their sticker and net prices were roughly two-thirds those of state colleges.
} 
When grant aid is taken into account, U. Mass. campuses charge their students an average of $\$ 8,000$ a year, relative to the $\$ 15,000$ charged by their competitors. Students, particularly those facing credit constraints, may thus make a seemingly rational decision to forgo college quality in order to attend a lower-cost public option 18

Table A.1 provides specific examples of four-year colleges commonly attended by the Massachusetts high school class of 2004. In 2004, U. Mass. Amherst, the college most commonly attended by Adams Scholarship recipients, had a four-year graduation rate of $43 \%$ and almost perfectly average overall quality. The other Adams colleges had substantially lower graduation rates and overall quality. Non-Adams colleges similar in graduation rate and quality to U. Mass. Amherst include Johnson \& Wales University and Merrimack College in the private sector and the University of Connecticut, the University of Vermont and the University of New Hampshire in the out-of-state public sector. Elite private colleges which also enroll relatively large numbers of Massachusetts students, such as Boston University, Tufts University and Harvard University, have four-year graduation rates $50-100 \%$ higher than U. Mass. Amherst, perhaps because they attract more academically skilled students or because they spend three or more times the amount of money on student instruction.

\section{Empirical Strategy}

We now turn toward estimating the causal impact of the Adams Scholarship on students' college outcomes. Comparing outcomes of those eligible and ineligible for the Adams Scholarship would confound the impact of the scholarship with the fact that eligible students have higher academic skill than ineligible ones. We eliminate this source of omitted variable bias by using a regression discontinuity design that compares students just above and below the eligibility thresholds. Students just above and just below these thresholds should be similar to each other except for receipt of the scholarship. Though the scholarship may incentivize students to raise their test scores and qualify for the aid, there is little scope for manipulation of test scores around eligibility thresholds

\footnotetext{
${ }^{18}$ In Section 6, we describe the average cost trade-off calculations and show that despite initial savings, there are earnings losses even larger than the savings.
} 
for three reasons. First, the earliest cohorts of students took their MCAS exams prior to the announcement of the Adams Scholarship. Second, at the time of test administration, the district-level 75th percentile threshold is impossible for individual students to know precisely. Third, exams are centrally scored and raw scores transformed into scaled scores via an algorithm unknown to students, their families or teachers.

Figure 2 provides a graphical interpretation of scholarship eligibility in three types of school districts. In each type of district, the straight line with a slope of negative one represents the cutoff that determines whether a student's total MCAS scores (math + ELA) places her in the top 25\% of her school district. The W-shaped boundary defines the region in which students have scored "advanced" in one subject and "proficient" or "advanced" in the other. In low-performing districts with $25 \%$ cutoff scores of at most 500 , that cutoff is so low that passing the proficient/advanced threshold is sufficient (and necessary) to win a scholarship. In medium-scoring districts with 25\% cutoff scores between 502 and 518, that cutoff and proficient/advanced threshold interact in a complex way. In high-performing districts with $25 \%$ cutoff scores of at least 520, that cutoff is so high that passing it is sufficient to win. Scholarship winners are those students whose test scores thus fall in the shaded region of the graph. We note here that MCAS scores have risen dramatically since the inception of the program, as shown in Figure A.5. Because so many students pass the proficient/advanced threshold, relatively few districts in our sample are low-performing as defined by Figure 2. In other words, it is the top $25 \%$ boundary that is generally of the greatest importance, which can be seen by the fact that a full $25 \%$ of students qualify for the scholarship each year.

There are many strategies for dealing with multidimensional regression discontinuities, as discussed by Reardon and Robinson (2012). Examples of such situations in the economics of education include Papay et al. (2010, 2011a b). We collapse the discontinuity into a single dimension by defining for each student the distance of her math score from the minimum math score that defines eligibility, given her school district and ELA score. In Figure 2, this can be thought of as the horizontal distance between the point defined by each student's pair of test scores and the dark 
line defining the eligibility threshold in her school district ${ }^{19}$ We use raw scores rather than scaled scores in defining the running variable for two reasons. First, the raw scores are a finer measure of skill than the scaled score bins into which they are collapsed. Second, we observed extreme bunching in values of the scaled scores, particularly around the values that define the proficient and advanced thresholds. This bunching is driven entirely by the way that Massachusetts assigns groups of raw scores into scaled score bins, as the raw scores themselves have the extremely smooth distributions seen in Figures A.6 and A.7 20

As a result, the density of the running variable shown in Figure 3 looks largely smooth, suggesting little scope for endogenous manipulation that would violate the assumptions underlying the regression discontinuity design (McCrary, 2008). We do, however, see a small spike at zero itself, which is driven by the fact that a district's $75 \%$ threshold is mechanically more likely to fall on test scores that are more common in that district. Figure A.8 is consistent with this fact, showing that no such spike occurs in the low-performing districts for which only the proficient/advanced threshold, and not the $75 \%$ threshold, defines the boundary ${ }^{21}$ Though the spike is small and not driven by endogenous manipulation of the running variable itself, we later show that our central results are robust to and even strengthend by excluding students directly on the boundary, in a so-called "doughnut hole" regression discontinuity.

To estimate the causal effect of the Adams Scholarship, we use local linear regression to estimate linear probability models of the form:

$$
Y_{i j t}=\beta_{0}+\beta_{1} A_{d a m s_{i j t}}+\beta_{2} G_{a p_{i j t}}+\beta_{3} G a p_{i j t} \times A d a m s_{i j t}+\epsilon_{i j t} .
$$

where Gap $_{i j t}$ is the running variable described above and Adams is an indicator for Adams Scholarship eligibility $\left(\right.$ Gap $\left._{i j t} \geq 0\right){ }^{22}$ The causal effect of winning the Adams Scholarship on an out-

\footnotetext{
${ }^{19}$ Our results are robust to defining the running variable as the vertical distance, the distance of each student's ELA score from the minimum ELA score that defines eligibility, given her school district and math score.

${ }^{2}$ Goodman (2008) characterized each student by the minimum of her scaled score distance from the proficient/advanced and top $25 \%$ thresholds. Distance to the top $25 \%$ threshold is not an easily defined quantity when raw scores are used because the straight line boundary observed in Figure 2 becomes quite jagged. We therefore prefer the running variable described in the text above. Estimates using the running variable as defined in Goodman (2008) are, nonetheless, quite similar to those presented here and are available by request from the authors.

${ }^{21}$ Figure A.9 show very similar patterns for the 2005-08 sample.

${ }^{22}$ We use linear probability models here and in our later IV regressions rather than limited dependent variable models
} 
come, $Y_{i j t}$, should be estimated by $\beta_{1}$ if the usual assumptions underlying the validity of the regression discontinuity design are not violated. Assuming that treatment effects are homogeneous along different parts of the eligibility threshold, this coefficient measures a local average treatment effect for students near the threshold, weighted by the probability of a given student being near the threshold itself (Reardon and Robinson, 2012).

Our preferred implementation uses local linear regression with an triangular kernel that weights points near the threshold more heavily than those far from the threshold. We compute optimal bandwidths following the procedure developed by Imbens and Kalyanaraman (2012), which trades off precision for bias generated by deviations from linearity away from the threshold. Across nearly all of our outcomes and samples, the optimal bandwidth generated by this procedure falls somewhere between 10 and 15 raw score points. For simplicity and ease of defining a single sample across outcomes, we choose as our default specification a bandwidth of 12 . We then show that our results are quite robust to a wider set of bandwidths, to inclusion of demographic controls, to inclusion of school district by cohort fixed effects, and to use of parametric specifications, including polynomials of various degrees. We cluster standard errors by 12 th grade school district in all specifications in order to account for within district correlations in the error term $\epsilon_{i j t}$.

As further reassurance of the validity of the discontinuity design employed here, Table 3 tests whether observed covariates vary discontinuously at the eligibility threshold. The first eight columns test the basic covariates, including gender, race, low income, limited English proficiency and special education status. With the exception of marginally significant but small differences in the probability of being black or "other" race for the 2005-06 sample, none of those covariates shows a statistically significant discontinuity in either the 2005-06 or the 2005-08 sample. The estimates are precise enough to rule out economically significant discontinuities as well. To test whether these covariates are jointly discontinuous, we generate in columns 9 and 10 predicted math and ELA z-scores by regressing scores from the class of 2004 on the demographic controls listed in the previous eight columns. We then use the resulting regression estimates to predict

for the reasons discussed by Angrist (2001). In particular, we are interested in directly interpretable causal effects and not on structural parameters generated by non-linear models. We also note that estimates generated by probit and logit models turn out to be extremely similar to those generated by the linear probability model above. 
scores for students in subsequent classes. The estimates in columns 9 and 10 suggest no discontinuity in predicted test scores and the estimates are precise enough to rule out differences around the eligibility threshold of more than 0.02 standard deviations in academic skill. Figure 4 shows graphically the average predicted scores of students in each bin defined by distance from the eligibility threshold, confirming the lack of any clear difference in academic skill between students just above and just below the threshold in the 2005-06 sample ${ }^{23}$

\section{Results}

\subsection{Enrollment and Graduation Rates}

To visualize the enrollment impacts of the Adams Scholarship, we plot in Figure 5 the proportion of 2005-06 graduates for each value of Gap who enroll in four-year colleges immediately following high school graduation ${ }^{24}$ There is clear visual evidence that students at the eligibility threshold are substantially more likely to enroll in an Adams (i.e., in-state public) college than students just below the threshold. Such students are, however, similarly less likely to enroll in a non-Adams (i.e., in-state private or out-of-state) college, the net result of which is little apparent difference in overall college enrollment rates between these two groups of students.

The first row of Table 4 reports estimates of these differences in the 2005-06 sample. Scholarship eligibility induced 6.9 percent of students at the threshold to enroll in Adams colleges, a more than one-fourth increase over the 23.8 percent enrollment rate of students just below the threshold ${ }^{25}$ More than six-sevenths of these marginal students, or 6.0 percent, would have attended other fouryear colleges if not for the scholarship. The net result is a statistically insignificant 0.9 percentage point increase in the fraction of students enrolling in any four-year college. Many of these marginal students switched their enrollment from out-of-state colleges, leading to a 4.8 percentage point increase in the fraction of students enrolling in-state four-year colleges. The Adams Scholarship therefore did induce a substantial number of students to enroll in the public sector and succeeded

\footnotetext{
${ }^{23}$ The 2005-08 sample looks quite similar, as seen in Figure A.10

${ }^{24}$ Immediate enrollment was a requirement of the scholarship.

${ }^{25}$ Table A.2 shows that nearly half of these marginal students enrolled in U. Mass. Amherst, the flagship campus, and another third enroll in the various state colleges.
} 
in keeping some students in state who otherwise would have left.

The scholarship also induces a statistically insignificant 0.8 percentage point increase in the fraction of students who enrolled in two-year community colleges. That, combined with the slight rise in four-year college enrollment rates, implies that the scholarship raised overall immediate college enrollment rates by 1.7 percentage points. In the second row, we define as the outcome enrollment within two years of high school graduation, rather than immediately following graduation. The estimates in columns 1 and 3 fall by 0.6 and 0.9 percentage points respectively, suggesting that a small number of marginal students induced to enroll immediately in Adams colleges because of the scholarship would have enrolled within the next two years in the absence of the scholarship. The estimates in column 3 suggest that the scholarship may have accelerated enrollment in four-year colleges for a small number of students but did not induce enrollment in four-year colleges for any students who would not have enrolled within two years. Interestingly, the two-year college effect is unchanged by the shift in definition from immediate enrollment to enrollment within two years. This suggests that scholarship eligibility may have induced a small number of students to enroll in community colleges who would not otherwise have enrolled within two years.

Turning from enrollment to graduation, we plot in Figure 6 the proportion of students for each value of Gap who graduate from four-year colleges within six years of high school graduation. Students just above the eligibility threshold are more likely to have graduated from Adams colleges than those just below the threshold, an unsurprising result given that the former are much more likely to enroll in that sector than the latter. Scholarship eligibility also lowers graduation rates from non-Adams colleges, for the same reason that eligibility reduces initial enrollment in that sector. More surprising is that the decrease in graduation rates from non-Adams colleges is larger in magnitude than the increase in graduation rates from Adams colleges. The net result is that scholarship eligibility lowers overall graduation rates, as shown by the top line in Figure 6 . where points to the right of the eligibility threshold are generally lower than would be predicted if extrapolating from points to the left of the threshold 26

\footnotetext{
${ }^{26}$ One anomaly is that students exactly on the threshold $(G A P=0)$ have higher graduation rates than students just to the left of the threshold $(G A P=-1)$. We believe this is either an artifact of noisy data or driven by the slight bunching
} 
The third through fifth rows of Table 4 confirm this decrease in graduation rates. The third row uses as an outcome an indicator for the student being enrolled in a given college sector as of the spring of the fourth year after her high school graduation, which we interpret as a measure of persistence. The fourth and fifth rows use as outcomes indicators for whether a student has graduated from a given college sector within four or six years. The three rows tell a consistent story. Though scholarship eligibility increased enrollment in Adams colleges by nearly seven percentage points, it increased persistence and six-year graduation rates by only three percentage points, suggesting that the majority of marginal students did not successfully graduate from that sector. Scholarship eligibility reduced persistence and graduation rates in the private sector by over five percentage points. The net result is that scholarship eligibility reduced the probability of earning a four-year college degree within six years by 2.5 percentage points. That the persistence and four-graduation rate measures show similar declines suggests this is not merely a matter of delaying graduation but instead is driven by a subset of students who have dropped out of the four-year college sector entirely.

We note three other important findings. First, although scholarship eligibility increased the number of students enrolling in state, it had no ultimate effect on the probability of earning a degree in state. Second, none of the increased enrollment in community colleges translated into increased completion of two-year college degrees, even six years out of high school. Third, as a result, scholarship eligibility lowered by 2.5 percentage points the probability that a student had any college degree six years after high school graduation.

Table 5 explores these enrollment and graduation impacts over time, with the first four columns analyzing each high school class separately, the fifth pooling the classes of 2005-08, and the sixth showing enrollment effects for the classes of 2009-11, the most recent for which data are available. Panel A shows that scholarship eligibility increased enrollment in four-year Adams colleges for all graduating high school classes. There is, however, a gradual monotonic decrease in the impact

at zero described earlier in the text. Regression estimates that we discuss below, which show a clear discontinuity in the overall graduation rate, become even larger in a "doughnut hole" regression that excludes students on the threshold. For evidence of this, see Table A.3 Though not show here, difference-in-difference estimates that use the 2004 cohort as a pre-policy control group show similarly negative impacts on graduation rates, confirming that students to the right of the threshold are graduating at lower rates than would otherwise be predicted. 
of scholarship over time, with the effect in 2005 three times that of the effect over 2009-11. This gradually shrinking effect size may be driven by the fact that rapidly rising fees have shrunk the proportion of college costs covered by the scholarship. Also worth noting is that much of increase in overall four-year college enrollment is driven by the first treated class, with subsequent classes showing smaller and insignificant impacts on this margin.

Panel B estimates the impact of scholarship eligibility on persistence and graduation after four, five and six years. Three findings are worth noting. First, that the magnitude of the persistence and various graduation rates do not vary much within classes implies that the negative impact of scholarship eligibility on graduation rates is driven largely by dropout rather than delay. Second, that the negative graduation effect is not driven solely by the first high school class makes much less likely the possibility that the effect was generated by confusion about the meaning of "free tuition" in the scholarship letter. If such language was deceiving students into making uninformed decisions, we would expect such negative graduation effects to diminish across classes as information about the true value of the scholarship spread. There is no clear evidence of such a pattern. Third, estimated impacts on enrollment and persistence rates generated by the full 2005-08sample are similar to those generated by the 2005-06 sample. Figures A.11 and A.12 confirm this, replicating Figures 5 and 6 for the larger sample. The two sets of figures look quite similar. As a whole, this evidence suggests a fairly stable impact of the scholarship on enrollment, persistence and graduation.

Table A.3 tests the robustness of our central results to a variety of alternative specifications. Panel A replicates our default local linear regression specification for a variety of bandwidths, beginning with the Imbens-Kalyaramanan optimal bandwidth. In the 2005-06 sample, that optimal bandwidth is about 14 for enrollment outcomes and about 10 for persistence and graduation outcomes, hence our choice of 12 as the default bandwidth in earlier tables. The magnitude and statistical significant of these estimates are generally quite robust to these changes in the bandwidth.

Panel B replicates our default specification, using a bandwidth of 12 , with three variations. First, we include school district by high school class fixed effects to account for the fact that the 
eligibility threshold differs by district and class. This has very little impact on the estimates. Second, we include demographic controls, which also change the estimates very little. Third, we run a doughnut hole regression in which we exclude students exactly on the boundary, because of the small amount of bunching observed in the running variable. This actually increases the magnitude of our enrollment and graduation estimates by roughly a percentage point, suggesting that the mild bunching was, if anything, causing us to underestimate the impacts of the scholarship. Finally, panel C fits quadratic, cubic and quartic polynomials on either side of the threshold, using the entire sample and a rectangular kernel. This yields similar estimates to those generated by the local linear regression used as our default specification.

As a final piece of evidence, Figure 7 exploits as a placebo test data from the high school class of 2004, the one cohort in our data that graduated prior to the scholarship's existence. In panel A, we see no evidence of a discontinuity in Adams college enrollment for the class of 2004, compared to the previously observed clear discontinuity for the classes of 2005-06. Similarly, panel B shows that students below the threshold have similar six-year graduation rates across the three classes, whereas students above the threshold in 2005-06 have lower rates than such students in 2004. That the discontinuities in enrollment and graduation appear only in the years when the scholarship existed strengthens the case that it is due to the policy itself and not other unobserved factors.

Panel A also highlights that the magnitude of the enrollment impact is large even for students somewhat far from the threshold. Our regression discontinuity estimates, as well as those based on difference-in-difference calculations following Figure 7, suggest that the Adams Scholarship induced about 1,000 additional students to enroll in in-state public colleges. IPEDS data reported by Massachusetts' public colleges themselves confirms this. Figure 8 plots the reported freshman enrollment across all Massachusetts public four-year colleges, both for all students and for those from Massachusetts. There is a clear trend break in 2005, when the Adams Scholarship begins, due entirely to increased numbers of Massachusetts freshman and of magnitude nearly identical to our estimate. This implies that the additional students induced into in-state public colleges did not crowd out other students, instead simply adding to each campus at most a few hundred students who would not otherwise have enrolled there. 
In summary, the primary effect of the Adams Scholarship was to induce large numbers of students to switch into in-state public four-year colleges from other four-year colleges they otherwise would have attended, a result consistent with Goodman (2008). The scholarship did increase in-state college enrollment rates but had little impact on in-state graduation rates. Scholarship eligibility actually reduced overall graduation rates, for reasons we now turn to.

\subsection{College Quality and Cost}

The most plausible explanation for the negative impacts on graduation rates is that the scholarship induced students to attend colleges with substantially lower graduation rates than they otherwise would have. Table 6 explores the quality and cost tradeoffs that the Adams Scholarship induced. The top row presents reduced form estimates of the impact of scholarship eligibility on a variety of college quality and cost measures, as in Equation 1 above. For this analysis, we assign students to the four-year college to which they enroll immediately following high school graduation. The bottom row estimates these impacts for the marginal student using the following equations that instrument enrollment in an in-state public college with scholarship eligibility:

$$
\begin{gathered}
Y_{i j t}=\beta_{0}+\beta_{1} \text { Adams } \hat{C o l l e g e}_{i j t}+\beta_{2} \text { Gap }_{i j t}+\beta_{3} \text { Gap }_{i j t} \times \text { Adams }_{i j t}+\epsilon_{i j t} \\
\text { AdamsCollege }_{i j t}=\alpha_{0}+\alpha_{1} \text { Adams }_{i j t}+\alpha_{2} \text { Gap }_{i j t}+\alpha_{3} \text { Gap }_{i j t} \times \text { Adams }_{i j t}+\nu_{i j t}
\end{gathered}
$$

In the first column, we generate an indicator for a college being highly competitive if Barron's 2009 rankings placed that college into one of its top three categories of "most competitive," "highly competitive," and "very competitive,". None of Massachusetts' public colleges fall into these categories, which include colleges such as Boston University, Tufts University, Simmons College, and Lesley University. All of the U. Mass. campuses and nearly all of the state colleges fall into the fourth category of "competitive," which also includes private colleges such as Suffolk University and the Wentworth Institute of Technology. The fifth category of "not competitive" includes two state colleges and all community colleges. Column 1 shows that, for the classes of 2005-06, scholarship eligibility induced an estimated $3.3 \%$ of students, or $48 \%$ of those switching colleges, to forgo 
institutions in those highest three categories. Students did not simply switch into the public sector from private or out-of-state colleges of similar quality. Half of the students induced to switch colleges would have enrolled in more competitive alternatives in the absence of the scholarship.

Other measures of college quality, which are defined only for students immediately enrolling in four-year colleges, point to a similar pattern. In column 2, the estimates suggest that students induced by the scholarship to switch into Adams colleges would otherwise have attended colleges with four-year graduation rates nearly 17 percentage points higher. These marginal students would also have attended colleges with higher SAT math scores (by 27 points) and higher instructional spending per student (by $\$ 3,700$ annually), though this last estimate is not statistically significant. Combining these three measures as described above, column 5 shows that scholarship eligibility induced the marginal student to forgo more than 0.6 standard deviations in college quality.

In exchange for this drop in quality, students enrolled in public colleges where the average student's net price of attendance was $\$ 10,000$ a year lower than private and out-of-state alternatives, as seen in column 6 . This is the most direct measure we provide of the extent to which this in-kind subsidy reduces consumption of college education, as in Peltzman (1973). This cost difference would, however, have been available to these students even in the absence of the Adams Scholarship. The scholarship itself was worth, on average, less than $\$ 1,400$ a year to such students, as seen in column 72 Combining the estimates from columns 5 and 7 suggests a willingness to forgo $0.47(0.637 / 1.353)$ standard deviations of college quality per $\$ 1,000$ in annual aid. Estimates for the larger sample of 2005-08 graduates are quite similar. Below, we calculate the estimated impacts of such a tradeoff on lifetime earnings and find that these responses are hard to explain in classical human capital model. Students seem remarkably willing to forgo college quality and attend institutions with low graduation rates in exchange for relatively small amounts of financial aid.

To strengthen our case that the decrease in college quality induced by the scholarship explains the observed graduation impacts, we explore heterogeneity by a variety of characteristics in Table

\footnotetext{
${ }^{27}$ This is a weighted average of enrollment across all of the in-state public four-year colleges, where the value of the scholarship ranged from \$1,417-\$1,714 at U. Mass. campuses and \$910-\$1,030 at state colleges.
} 
7. Here we use the classes of 2005-08 to improve precision among relatively small subgroups. Panel A takes advantage of the fact that the academic skill level defined by eligibility threshold varied by school district due to the requirement that students be in the top $25 \%$ of their district peers. We therefore divide districts into quintiles by the fraction of 2004 graduates who attended a competitive college, as defined previously. We then fully interact our baseline specification from prior tables with indicators for being from the bottom quintile, middle three quintiles, and top quintile of school districts, and also include the direct effects of those indicators.

For students from the bottom quintile districts, who are on average lower income and less academically skilled, scholarship eligibility increases enrollment in Adams colleges by nearly eight percentage points, of which five percentage points represent students who would not otherwise have enrolled immediately in any four-year college. Eligibility does not, however, reduce such students' probability of attending a highly competitive college likely because they would not have applied to or gained admission to such institutions. In the absence of the scholarship, these students would be attending four-year colleges of similar quality to the Adams colleges, or none at all. For these students, eligibility has no statistically significant impact on persistence and graduation on persistence, with point estimates that are slightly positive. The Adams Scholarship substantially increases college enrollment for such students, has little impact on college quality, and little impact on persistence and graduation.

Students from the top quintile districts barely react to this aid at all. There is no statistically significant evidence that they enroll in Adams colleges at higher rates, forgo highly competitive colleges, or persist or graduate at lower rates as a result of scholarship eligibility. Such students do not react presumably because they are wealthier on average and because their alternative college options are so much higher quality than the Adams colleges that the scholarship is insufficient incentive to switch.

Students from the middle quintile districts do react strongly to the aid. Eligibility raises enrollment in Adams colleges by nearly seven percentage points. Little or none of this comes from students enrolling in four-year colleges who would not have otherwise. Strikingly, two-fifths $(.026 / .068)$ of those marginal students who switch into Adams colleges do so by forgoing highly 
competitive colleges, unlike students from bottom or top districts. And, unlike students from bottom or top districts, only these students have clearly lower persistence and graduation rates as a result of scholarship eligibility. Unlike students from the lowest scoring districts, who are induced by the Adams Scholarship to switch sectors but not college quality level and have no graduation effects, students from middle districts are induced to forgo college quality and are the only students whose graduation rates suffer. This strengthens the case that college quality explains the scholarship's negative graduation effect.

The remaining three panels in Table 7/explore heterogeneity by student race/ethnicity, poverty and gender. Scholarship eligibility has a substantially stronger impact on non-white students' enrollment decisions than on white students' enrollment decisions. For non-white students, eligibility increases enrollment in an Adams college by over 13 percentage points, half of whom are students who would not otherwise have enrolled in a four-year college at all. For white students, eligibility increases Adams college enrollment by only five percentage points, nearly all of whom would have otherwise have enrolled in another four-year college. White students are the only ones who forgo more competitive colleges and see their persistence rates suffer. Non-white students do not forgo more competitive colleges and do not see a drop in their persistence rates. Roughly similar patterns are seen with poor and non-poor students. There are no statistically significant differences by gender. Taken as a whole, these results suggest that the observed negative impacts on graduation rates are concentrated in subgroups of students who are induced to forgo college quality by scholarship eligibility.

Having shown that scholarship eligibility both induced students to forgo college quality and lowered their graduation rates, in Table 8 we directly estimate the impact of college quality on those graduation rates. For such estimates to be valid, the exclusion restriction must hold, namely that scholarship eligibility affects graduation rates only through the college quality channel. We consider two potential violations of this exclusion restriction. First, scholarship eligibility may affect not only marginal students but infra-marginal ones as well. Our estimates suggest that roughly three-fourths of scholarship users would have attended Adams colleges in the absence 
of the scholarship ${ }^{28}$ If the financial aid were changing their graduation rates, the IV estimates would confound that channel with the quality channel. We believe this is unlikely both because the amount of money involved here is small relative to the costs of college and because that small amount of additional aid should, if anything, help students graduate by allowing them not to work while on campus. If the graduation rates of infra-marginal students were improved by this aid, the coefficients below would actually underestimate the impact of college quality on the graduation rate of marginal students.

A second potential violation of the exclusion restriction could occur if the scholarship changed factors other than college quality for the marginal students. If, for example, switching to an Adams college and remaining in state increased the probability of living at home, our estimates might confound that channel with the college quality channel. We find that story unlikely as well, given that our effects are being driven largely by students attending the U. Mass. Amherst campus in western Massachusetts, which for most students is at least an hour's drive from home. We cannot, however, definitely rule out such violations of the exclusion restriction and, as such, present the calculations below only as suggestive estimates of the impact of college quality on graduation rates.

To use scholarship eligibility as an instrument for the different measures of college quality listed in each column, we run the following IV and first-stage equations:

$$
\begin{gathered}
{\text { GraduateIn } 4_{i j t}=\beta_{0}+\beta_{1} \text { College }_{\text {Quality }} i j t}+\beta_{2} \text { Gap }_{i j t}+\beta_{3} \text { Gap }_{i j t} \times \text { Adams }_{i j t}+\epsilon_{i j t} \\
\text { CollegeQuality }_{i j t}=\alpha_{0}+\alpha_{1} \text { Adams }_{i j t}+\alpha_{2} \text { Gap }_{i j t}+\alpha_{3} \text { Gap }_{i j t} \times \text { Adams }_{i j t}+\nu_{i j t}
\end{gathered}
$$

The first row of Table 8 provides the first stage coefficients by replicating the estimates seen in previous tables of the impact of scholarship eligibility on the given measure of college quality. The second row provides reduced form estimates by replicating the impact of scholarship eligibility on graduation rates from Tables 4 . The third row contains the instrumental variables estimates themselves, the ratios of the reduced form estimates to the first stage estimates. The final row

\footnotetext{
${ }^{28}$ The scholarship raised enrollment in in-state public colleges by seven percentage points from a base of 24 percentage points, as seen in Table 4 Calculations using tuitions instead of enrollment yield a similar ratio.
} 
shows the OLS estimate of the same relationship without using the instrument. For each sample, the first column measures the impact of attending an Adams college for all students, while the second column conditions the sample on those immediately enrolling in a four-year college. The third and fourth columns use institutional graduation rates and our quality index as quality measures, also conditioning the sample on those immediately enrolling in a four-year college for whom such measures are observed.

The magnitudes of the IV estimates are large. For the marginal student induced by the scholarship to attend in-state public college, attending such a college lowered the probability of graduating in six years by a remarkable 36 percentage points in the 2005-06 sample, or 27 percentage points when the sample is limited to enrollers. In the 2005-08 sample, attending an Adams college lowered four-year graduation rates by 17 percentage points, or 27 percentage points for enrollers. The IV estimates in columns 2 and 6 are similar in magnitude to and statistically indistinguishable from their OLS counterparts. The coefficients in columns 3 and 7 suggest that, for these marginal students, attending a college with a four-year graduation rate one percentage point higher would translate into a roughly 1.6 percentage point increase in graduation probabilities. Differences in college-level graduation rates translate more than one-for-one into individual-level graduation rates for this subset of students, although a value of one is well within the confidence intervals of these estimates and both IV estimates are statistically indistinguishable from their OLS counterparts. Finally, columns 4 and 8 suggest that attending a college of one standard deviation higher quality raises the probability of graduating by $43-56$ percentage points. This is roughly three times larger than the effect estimated in Long (2008) by OLS and by instrumenting college quality by the average quality of nearby colleges ${ }^{29}$ That these last IV estimates are so large suggests either that omitted variable bias is causing OLS estimates to understate quality effects, that our measures of college quality understate the true differences in quality between Adams and non-Adams colleges, or that the marginal student induced to switch college due to scholarship eligibility is more sensitive to college quality than the average student.

\footnotetext{
${ }^{29}$ See the first row of Table 6 in that paper.
} 


\section{Discussion}

Our findings are consistent with Peltzman's theoretical prediction that in-kind subsidies can actually reduce consumption of the subsidized good for some individuals. Our heterogeneity results indicate that this is particularly true for students from school districts in the middle of the college enrollment distribution. The increased subsidy provided by the Adams Scholarship induced a number of such students to enroll in the public sector, where they would be spending substantially less money on tuition and, relatedly, the institutions would be spending less money on instruction. In this sense, the program achieved one of its primary goals, to draw highly skilled students into the public colleges. It is unclear, however, whether students were aware that, by choosing institutions with fewer resources to spend on instruction, they were essentially induced by the scholarship to purchase less education than they otherwise would have.

Our estimates make it difficult to explain students' enrollment decisions through a classical human capital model in which the benefits and costs of various educational options are being weighed. According to our calculations based on the American Community Survey in Massachusetts, the lifetime earnings difference between those holding only B.A.s and those with only some college is slightly under $\$ 1,000,000$. Reducing one's probability of graduating by about 27 percentage points, as happened to marginal students using the scholarship, would therefore result in a $\$ 270,000$ expected lifetime earnings penalty. Separate from the graduation margin, Black and Smith (2006) estimate that a one standard deviation decrease in college quality is associated with a $4.2 \%$ decrease in earnings, or about $\$ 100,000$ for Massachusetts B.A. holders with average lifetime earnings of $\$ 2.5$ million. Attending a college of 0.5 standard deviations lower quality, as do marginal students here, thus results in an $\$ 50,000$ expected lifetime earnings penalty. Either of these penalties on its own, and both together, far outweigh the value of the tuition waiver, which is at most worth less than $\$ 7,000$. As such, many of these students' decisions likely failed a simple benefit-cost analysis.

We take this as strong evidence that these students did not fully understand the role of college quality in their enrollment decision. To be clear, we think that students likely understood the value of the scholarship itself, or at least were not overestimating its value. The scholarship's 
large and sustained enrollment impact over multiple cohorts suggest that students did not simply misunderstand the letter's promise of "four years of free tuition." Students' strong enrollment reaction have have been driven in part by the excitement of receiving aid with a formal name attached, as documented in Avery and Hoxby (2004). It is, of course, possible that some students were so financially constrained or had such high discount rates that switching into scholarship eligible institutions was a rational decision. Nonetheless, we find it more plausible that the marginal student did not understand that the role of college quality in this decision, either because she was unaware of quality differences between her college options or because she was aware but did not believe that such quality differences would affect her own graduation probability or labor market outcomes.

This work is unable to determine which, if either, of these two possibilities best explains the patterns observed here. Such distinction may be important, given that these two explanations have potentially different policy implications. If students properly understand the importance of college quality but are uninformed about actual quality differences, efforts to make such information more readily accessible may be fruitful. There has already been some movement on this front, with the 2013 release by the federal government of the College Scorecard website allowing students to quickly find and compare the graduation rates of various postsecondary institutions. If instead students are well-informed about such quality measures but discount their importance, efforts to make such measures more salient may improve college choices. The College Scorecard website implicitly does this by focusing students on a small number of measures, including graduation rates. We are, however, unaware of any clear empirical evidence on whether making college quality measures more readily available or more salient effects students' enrollment decisions.

This particular merit aid policy likely reduces social welfare. The program's costs are not listed in budget appropriations because the tuition waivers represent not expenditures but foregone revenue. The Board of Higher Education has, however, estimated that the total annual value of the waivers is roughly $\$ 13$ million ${ }^{30}$ Roughly three-fourths of these funds flow to infra-marginal stu-

\footnotetext{
${ }^{30}$ This estimate was communicated to us in a phone call. Our own calculations based only on the observed enrollment of Adams eligible students suggests the annual costs are closer to $\$ 25$ million. Assuming the state's number is correct, this large difference is likely generated by students who do not collect their scholarships due to failure to notify their colleges of the award, failure to file a FAFSA, or failure to maintain the necessary minimum GPA.
} 
dents who would have attended in-state public colleges in the absence of the scholarship. As a result of this and the low graduation rates of in-state public colleges, the scholarship has little or no impact on the number of college graduates Massachusetts produces each year. The scholarship also reduces by about 200 students per year the number of colleges degrees earned by Massachusetts high school graduates $\sqrt[31]{13}$ All in all, these considerations suggest the state is spending large amounts of money for little net benefit or even net harm to its students.

The only clear positive evidence we have presented, found in our heterogeneity analysis, is that this scholarship substantially increased college enrollment rates for the most disadvantaged students. Low income students, non-white students and students from the least college-oriented school districts saw their enrollment rates in four-year colleges increase by four to six percentage points. Such increased enrollment did not, however, appear to translate into increased graduation rates. More importantly, such students comprise an extremely small fraction of the total pool of those eligible for this merit aid, because of the strong negative relationship between those characteristics and standardized test scores. Most of the merit aid flowed to students who would have enrolled in college even without the scholarship.

\section{Conclusion}

We find that a relatively small amount of financial aid induces a large number of high-skilled students in Massachusetts to enroll in in-state public colleges. Many of these students forgo the opportunity to attend higher quality colleges and, in doing so, lower their own graduation rates. We argue that this is some of the clearest evidence to date that college quality likely plays an important role in determining whether students complete their degrees. This also provides a clear example of the theoretical prediction in Peltzman (1973) that in-kind subsidies of public institutions can reduce consumption of the subsidized good.

Our results highlight the importance of improving postsecondary institutions whose completion rates are low. Whether college quality operates through access to coursework, campus re-

\footnotetext{
${ }^{31}$ These calculations assume the local average treatment effect estimated in Table 4 applies to the entire population of about 15,000 Adams Scholarship recipients each year.
} 
sources, peer effects or other channels is beyond the scope of this paper. Deeper exploration of the institution-level factors preventing college completion is needed, as this work suggests that student characteristics alone are insufficient to explain the low rates of college completion currently observed in the U.S. 


\section{References}

Abdulkadiroglu, A., J. D. Angrist, and P. A. Pathak (2011). The elite illusion: Achievement effects at boston and new york exam schools. Technical report, National Bureau of Economic Research.

Andrews, R. J., J. Li, and M. F. Lovenheim (2012). Quantile treatment effects of college quality on earnings: Evidence from administrative data in texas. Technical report, National Bureau of Economic Research.

Angrist, J. D. (2001). Estimation of limited dependent variable models with dummy endogenous regressors. Journal of Business \& Economic Statistics 19(1).

Avery, C. and C. M. Hoxby (2004, September). Do and Should Financial Aid Packages Affect Students' College Choices?, pp. 239-302. University of Chicago Press.

Bailey, M. J. and S. M. Dynarski (2011, December). Gains and gaps: Changing inequality in u.s. college entry and completion. Working Paper 17633, National Bureau of Economic Research.

Bassok, D., M. Fitzpatrick, and S. Loeb (2012, December). Does state preschool crowd-out private provision? the impact of universal preschool on the childcare sector in oklahoma and georgia. Working Paper 18605, National Bureau of Economic Research.

Belley, P. and L. Lochner (2007). The changing role of family income and ability in determining educational achievement. Journal of Human Capital 1(1), 37-89.

Bettinger, E. P., B. T. Long, P. Oreopoulos, and L. Sanbonmatsu (2012). The role of application assistance and information in college decisions: Results from the h\&r block fafsa experiment. The Quarterly Journal of Economics 127(3), 1205-1242.

Black, D. and J. Smith (2004). How robust is the evidence on the effects of college quality? Evidence from matching. Journal of Econometrics 121(1), 99-124.

Black, D. and J. Smith (2006). Estimating the returns to college quality with multiple proxies for quality. Journal of Labor Economics 24(3), 701-728.

Bound, J., M. Lovenheim, and S. Turner (2010). Why have college completion rates declined? An analysis of changing student preparation and collegiate resources. American Economic Journal. Applied Economics 2(3), 129.

Bound, J. and S. Turner (2007). Cohort crowding: How resources affect collegiate attainment. Journal of Public Economics 91(5), 877-899.

Bowen, W., M. Chingos, and M. McPherson (2009). Crossing the finish line: Completing college at America's public universities. Princeton University Press.

Brand, J. and C. Halaby (2006). Regression and matching estimates of the effects of elite college attendance on educational and career achievement. Social Science Research 35(3), 749-770.

Brewer, D., E. Eide, and R. Ehrenberg (1999). Does it pay to attend an elite private college? Crosscohort evidence on the effects of college type on earnings. Journal of Human Resources 34(1), 104-123. 
Brown, J. R. and A. Finkelstein (2008). The interaction of public and private insurance: Medicaid and the long-term care insurance market. The American Economic Review 98(3), 1083-1102.

Bui, S. A., S. G. Craig, and S. A. Imberman (2011). Is gifted education a bright idea? assessing the impact of gifted and talented programs on achievement. Technical report, National Bureau of Economic Research.

Calcagno, J., T. Bailey, D. Jenkins, G. Kienzl, and T. Leinbach (2008). Community college student success:What institutional characteristics make a difference? Economics of Education Review 27(6), 632-645.

Cellini, S. R. (2009). Crowded colleges and college crowd-out: The impact of public subsidies on the two-year college market. American Economic Journal: Economic Policy 1(2), 1-30.

Chevalier, A. and G. Conlon (2003). Does it pay to attend a prestigious university? Working Paper 848, Institute for the Study of Labor (IZA).

Cornwell, C., D. B. Mustard, and D. J. Sridhar (2009). The enrollment effects of merit-based financial aid: Evidence from georgia's hope program. Journal of Labor Economics 24(4), 761-786.

Cutler, D. M. and J. Gruber (1996). Does public insurance crowd out private insurance? The Quarterly Journal of Economics 111(2), 391-430.

Dale, S. and A. Krueger (2002). Estimating the payoff to attending a more selective college: An application of selection on observables and unobservables. Quarterly Journal of Economics 117(4), 1491-1527.

Dale, S. and A. B. Krueger (2011, June). Estimating the return to college selectivity over the career using administrative earnings data. Working Paper 17159, National Bureau of Economic Research.

Deming, D. and S. Dynarski (2010). College aid. In Targeting investments in children: Fighting poverty when resources are limited, pp. 283-302. University of Chicago Press.

Deming, D., J. Hastings, T. Kane, and D. Staiger (2011). School choice, school quality and academic achievement. Working Paper 17438, National Bureau of Economic Research.

Dobbie, W. and R. G. Fryer (2011). Exam high schools and academic achievement: Evidence from new york city. Technical report, National Bureau of Economic Research.

Dynarski, S. (2000). Hope for whom? financial aid for the middle class and its impact on college attendance. National Tax Journal 53(3), 629-661.

Dynarski, S. (2008). Building the stock of college-educated labor. Journal of Human Resources 43(3), 576-610.

Fitzpatrick, M. D. and D. Jones (2012). Higher education, merit-based scholarships and postbaccalaureate migration. Technical report, National Bureau of Economic Research.

Ganderton, P. T. (1992). The effect of subsidies in kind on the choice of a college. Journal of Public Economics 48(3), 269-292. 
Goodman, J. (2008). Who merits financial aid?: Massachusetts' Adams Scholarship. Journal of Public Economics 92(10-11), 2121-2131.

Hoekstra, M. (2009). The effect of attending the flagship state university on earnings: A discontinuity-based approach. The Review of Economics and Statistics 91(4), 717-724.

Imbens, G. and K. Kalyanaraman (2012). Optimal bandwidth choice for the regression discontinuity estimator. The Review of Economic Studies 79(3), 933-959.

Kane, T. (2007). Evaluating the impact of the DC Tuition Assistance Grant program. Journal of Human Resources 42(3), 28.

Kane, T. J. (2006). Public intervention in post-secondary education. Handbook of the Economics of Education 2, 1369-1401.

Lang, K. and E. Siniver (2011). Why is an elite undergraduate education valuable? Evidence from Israel. Labour Economics 18(6), 767-777.

Leigh, D. and A. Gill (2003). Do community colleges really divert students from earning bachelor's degrees? Economics of Education Review 22(1), 23-30.

Long, B. T. (2004, August). Does the format of a financial aid program matter? the effect of state in-kind tuition subsidies. Review of Economics and Statistics 86(3), 767-782.

Long, M. (2008). College quality and early adult outcomes. Economics of Education Review 27(5), 588-602.

Loury, L. and D. Garman (1995). College selectivity and earnings. Journal of Labor Economics 13(2), 289-308.

McCrary, J. (2008). Manipulation of the running variable in the regression discontinuity design: A density test. Journal of Econometrics 142(2), 698-714.

Pallais, A. (2009). Taking a chance on college is the tennessee education lottery scholarship program a winner? Journal of Human Resources 44(1), 199-222.

Papay, J. P., R. J. Murnane, and J. B. Willett (2010, March). The consequences of high school exit examinations for low-performing urban students: Evidence from Massachusetts. Educational Evaluation and Policy Analysis 32(1), 5-23.

Papay, J. P., J. B. Willett, and R. J. Murnane (2011a). Extending the regression-discontinuity approach to multiple assignment variables. Journal of Econometrics 161, 203-207.

Papay, J. P., J. B. Willett, and R. J. Murnane (2011b, June). High-school exit examinations and the schooling decisions of teenagers: A multi-dimensional regression-discontinuity approach. Working Paper 17112, National Bureau of Economic Research.

Peltzman, S. (1973). The effect of government subsidies-in-kind on private expenditures: The case of higher education. The Journal of Political Economy 81(1), 1-27.

Reardon, S. F. and J. P. Robinson (2012). Regression discontinuity designs with multiple ratingscore variables. Journal of Research on Educational Effectiveness 5(1), 83-104. 
Reynolds, C. L. (2012). Where to attend? Estimating the effects of beginning college at a two-year institution. Economics of Education Review 31(4), 345-362.

Rouse, C. (1995). Democratization or diversion? The effect of community colleges on educational attainment. Journal of Business \& Economic Statistics 13(2), 217-224.

Sandy, J., A. Gonzalez, and M. Hilmer (2006). Alternative paths to college completion: Effect of attending a 2-year school on the probability of completing a 4-year degree. Economics of Education Review 25(5), 463-471.

Stange, K. (2009). Ability sorting and the importance of college quality to student achievement: Evidence from community colleges. Education Finance and Policy 7(1), 1-32. 
Figure 1: Time to Graduation by Four-Year College Sector, Class of 2004

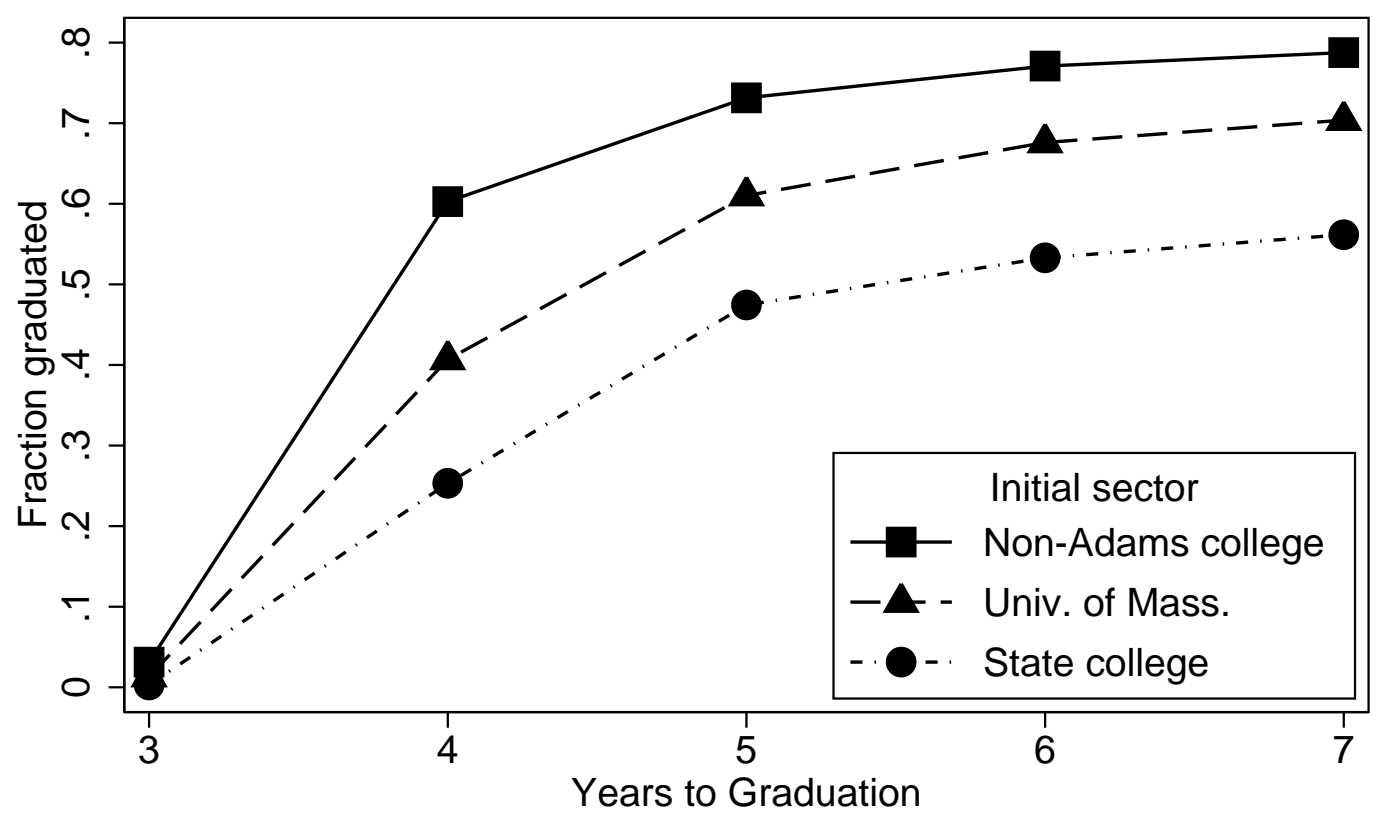

Notes: The above figure shows the time to graduation by initial college sector for all 2004 Massachusetts high school graduates who enroll in college immediately following high school graduation. Calculations are based on National Student Clearinghouse data. 
Figure 2: Graphical Representation of the Eligibility Threshold

(A) Low-scoring district

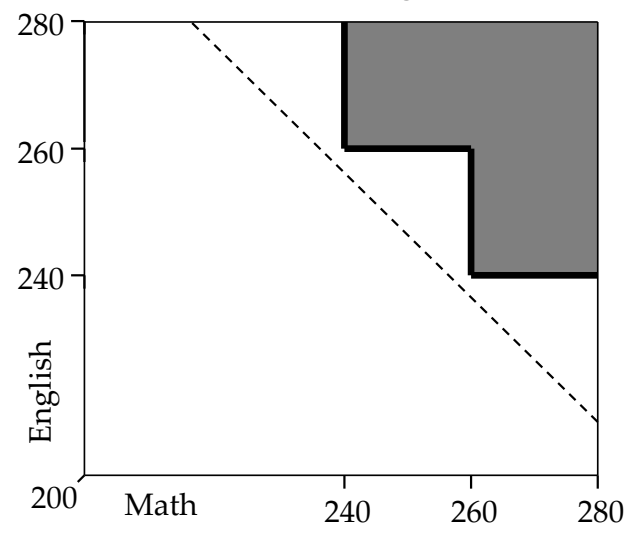

(B) Medium-scoring district

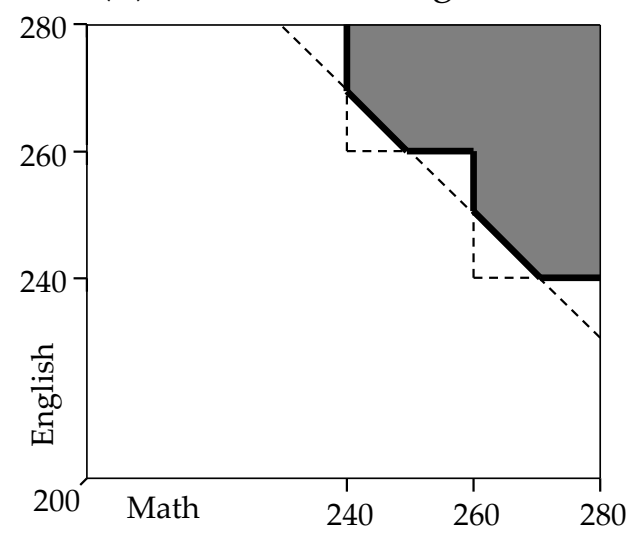

(C) High-scoring district

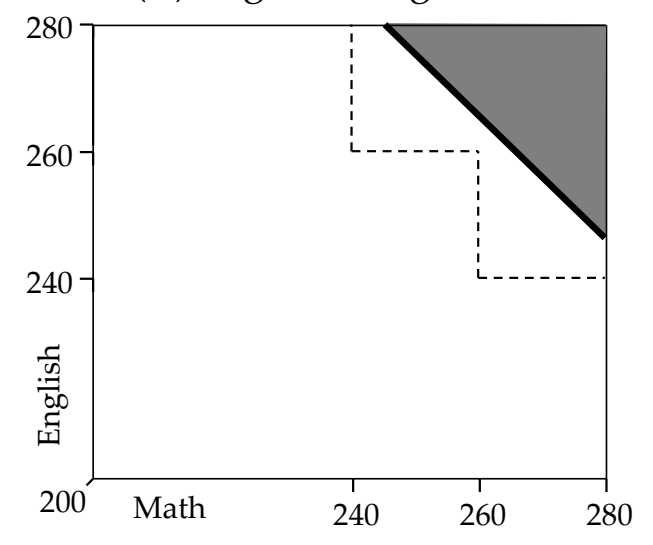

Notes: Each panel shows a graphical representation of the set of students who are eligible for the Adams Scholarship in various types of school districts, based on scaled MCAS scores. Panel A shows a district whose 75th percentile total score is less than 500. Panel B shows a district whose 75th percentile is between 500 and 520. Panel C shows a district whose 75th percentile score is above 520 . 
Figure 3: Density of Running Variable, Classes of 2005-06

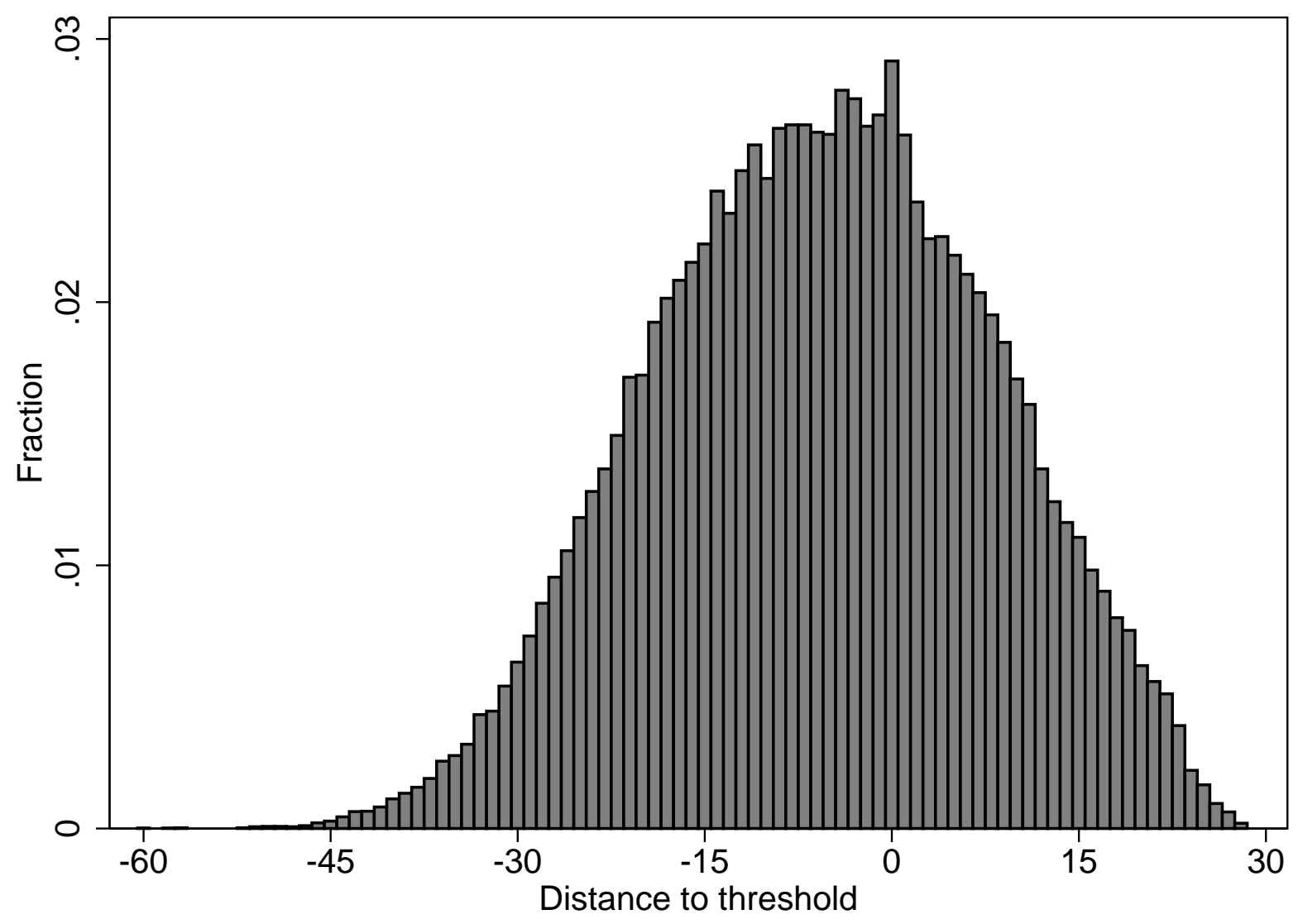

Notes: The above figure shows the distribution of the running variable for the high school classes of 2005-06. The running variable is defined as the distance of a given student's raw math score from the raw math score defining her school district's threshold, given her raw ELA score. 


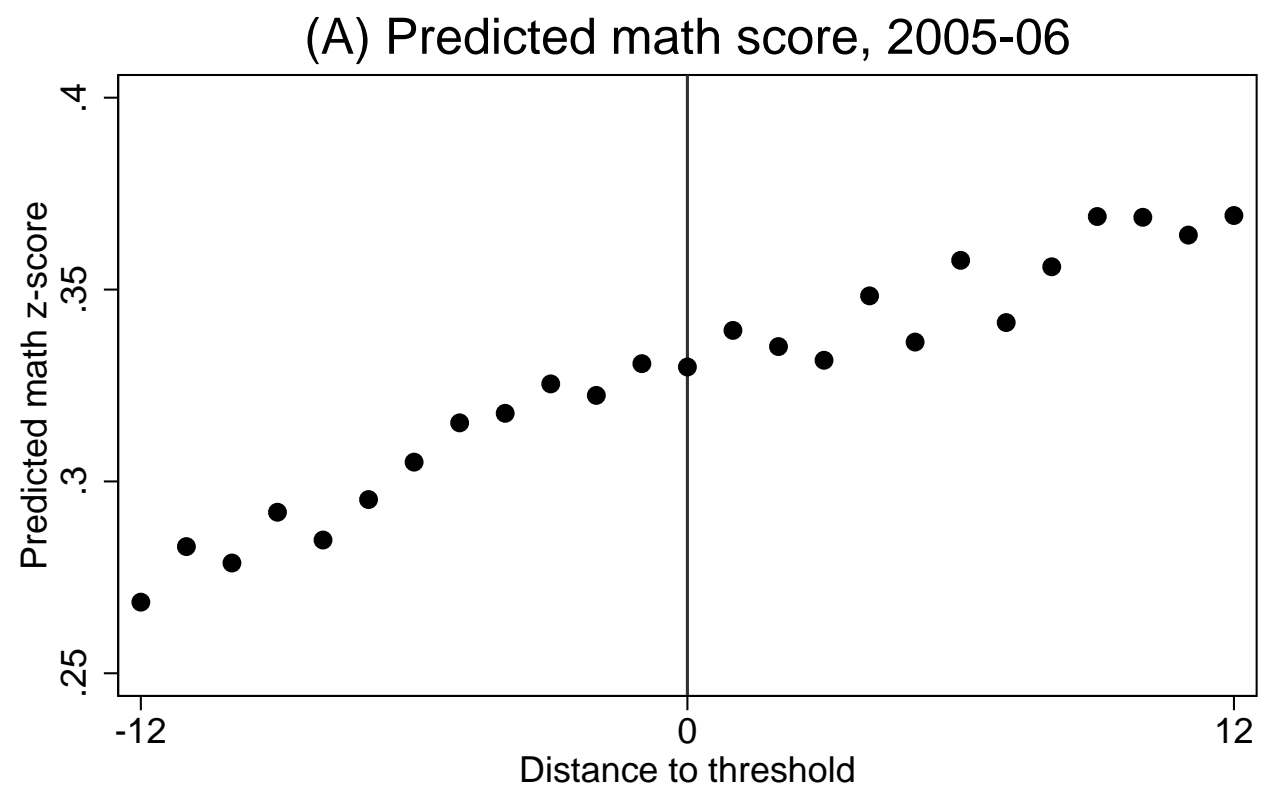

(B) Predicted ELA score, 2005-06

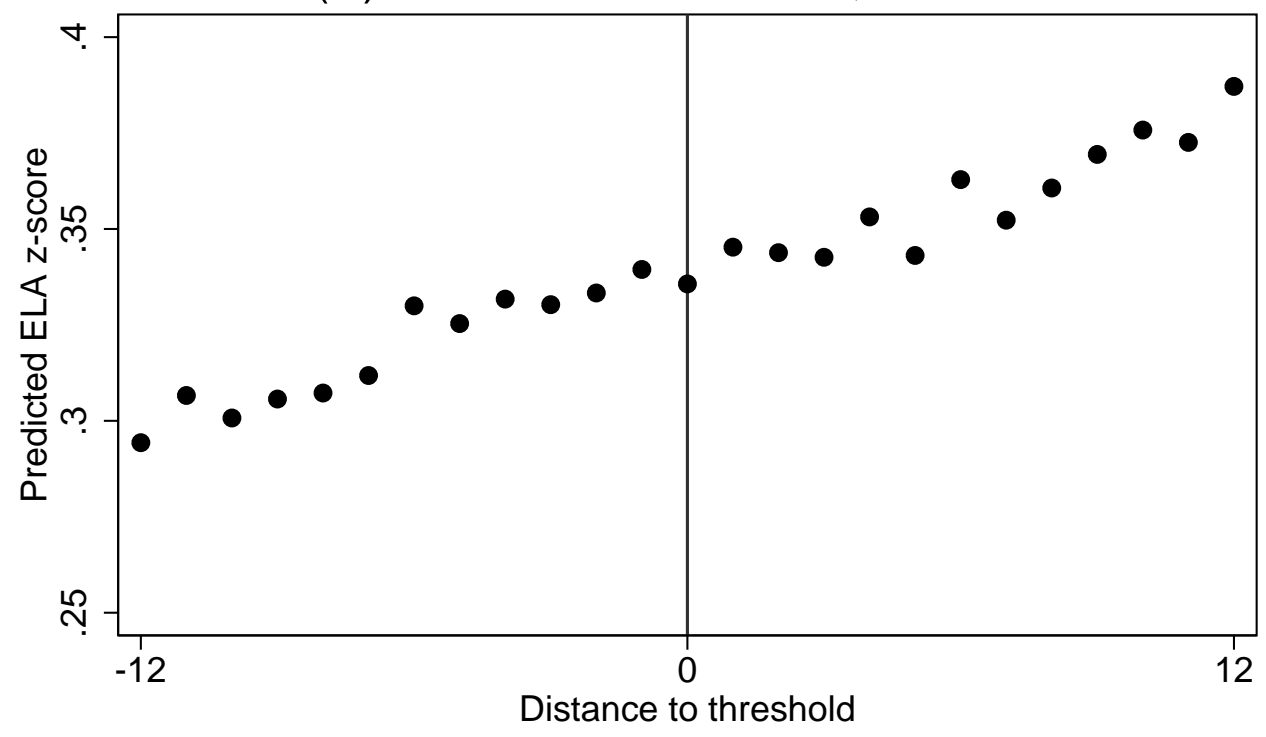

Notes: Each panel shows the mean predicted math and ELA score by each value of the running variable, for the high school classes of 2005-06. Predicted scores are generated by regressing math and ELA scores on demographic characteristics for the class of 2004. The resulting coefficients are then used to generate predictions for subsequent classes. 
Figure 5: Enrollment at Four-Year Colleges, Classes of 2005-06

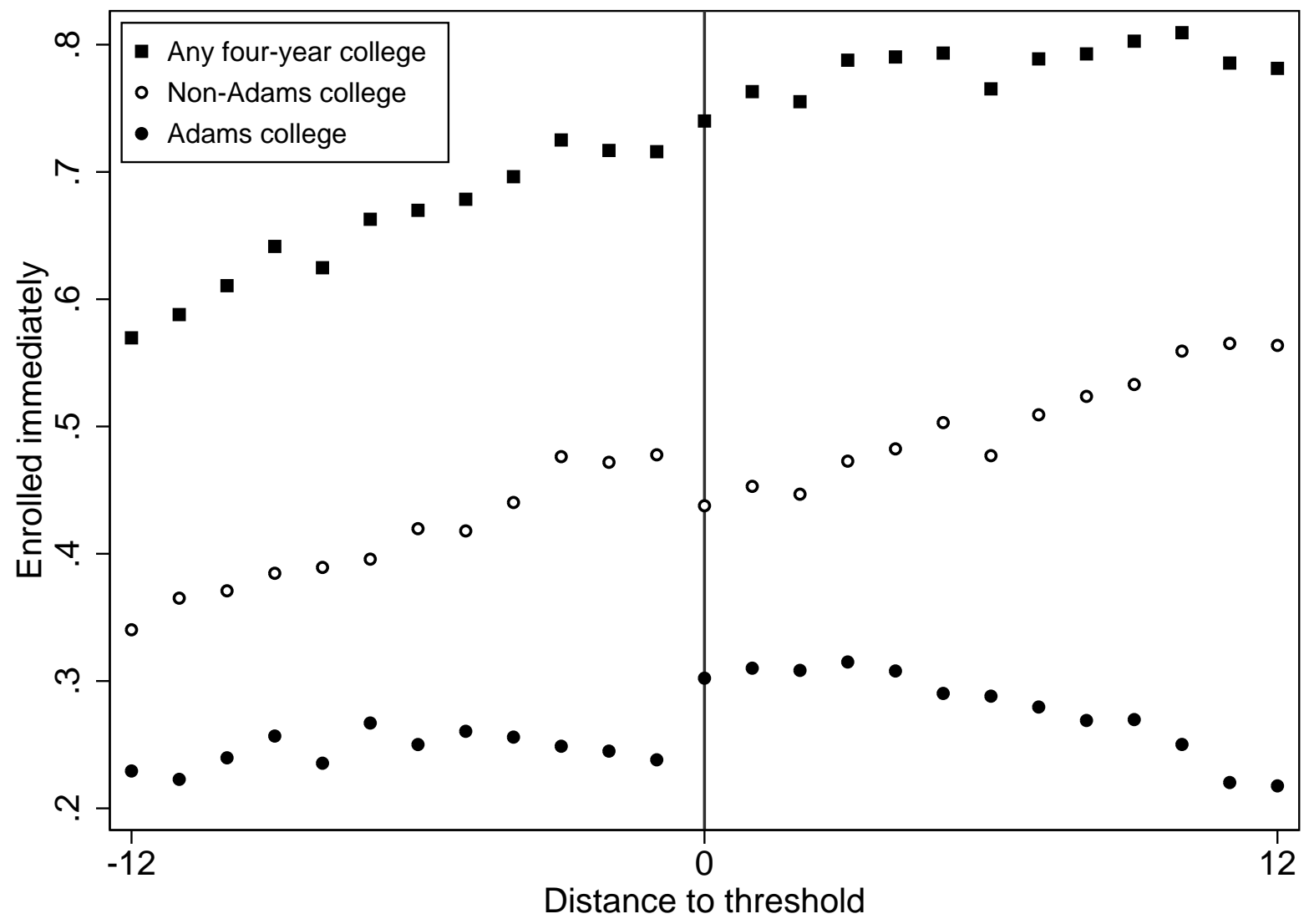

Notes: The above figure shows the fraction of students enrolling in four-year colleges immediately following high school graduation by each value of the running variable, for the high school classes of 2005-06. Adams colleges are Massachusetts public four-year colleges where the Adams Scholarship tuition waiver may be used. Non-Adams colleges are all other four-year colleges, both in-state and out of state. Calculations are based on National Student Clearinghouse data. 
Figure 6: Graduation from Four-Year Colleges, Classes of 2005-06

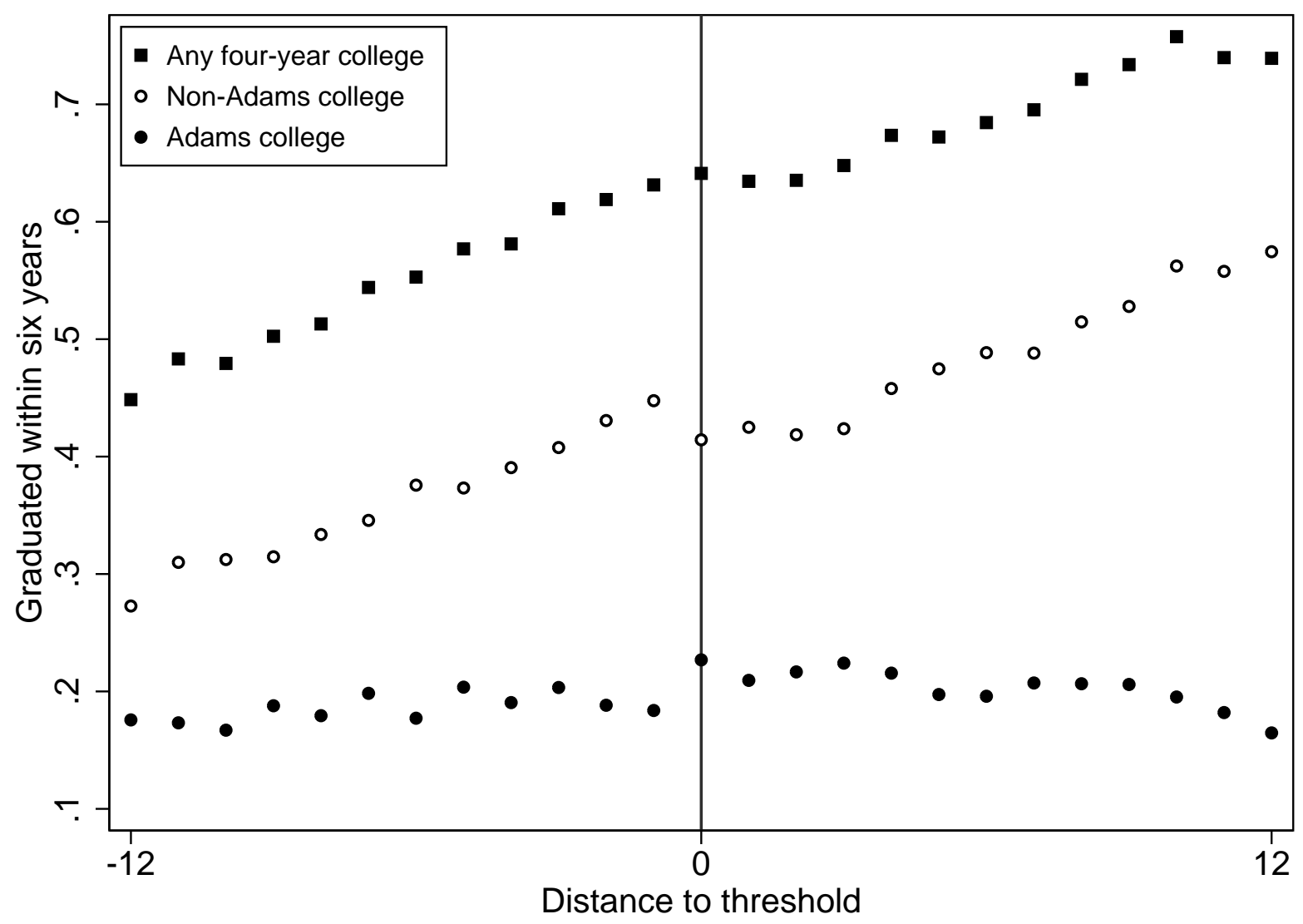

Notes: The above figure shows the fraction of students graduating from four-year colleges within six years of high school graduation by each value of the running variable, for the high school classes of 2005-06. Adams colleges are Massachusetts public four-year colleges where the Adams Scholarship tuition waiver may be used. Non-Adams colleges are all other four-year colleges, both in-state and out of state. Calculations are based on National Student Clearinghouse data. 
Figure 7: Treatment vs. Pre-Treatment Classes

(A) Enrolled Immediately in Adams College

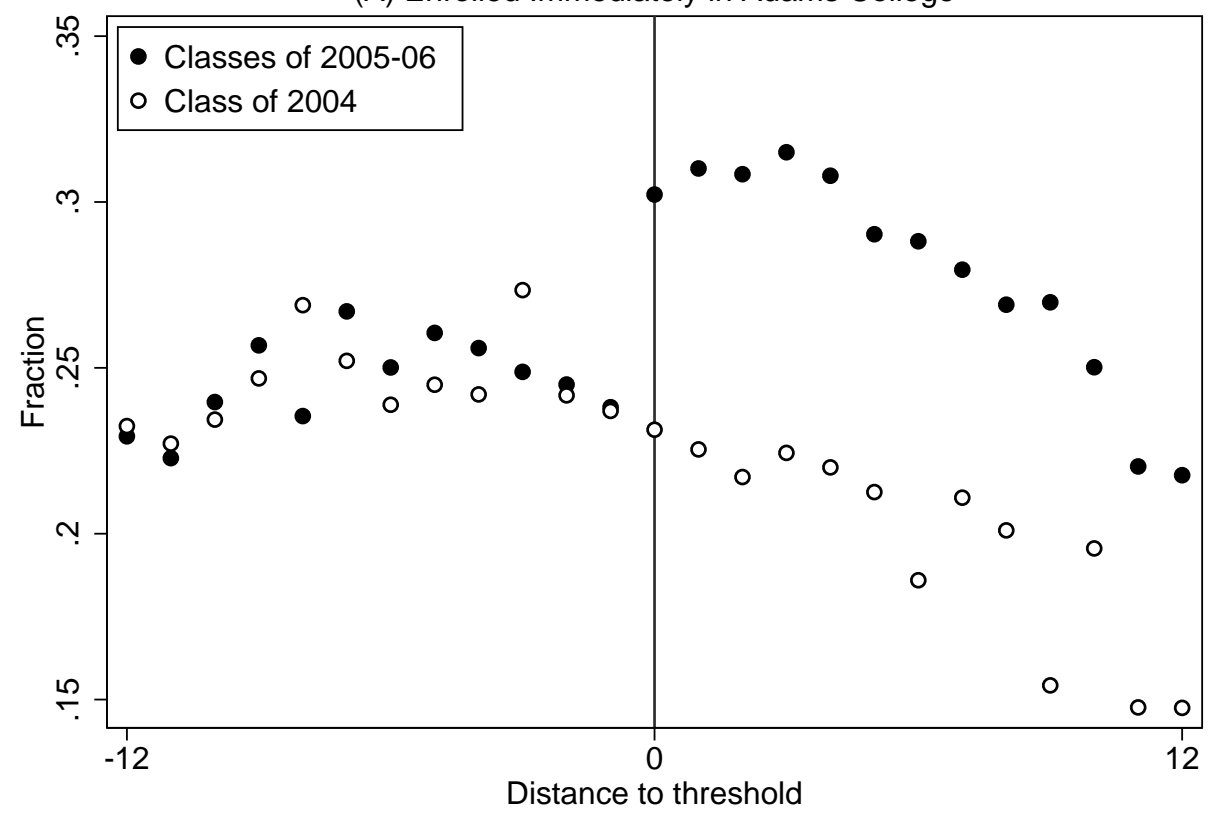

(B) Graduated within 6 Years from 4-Year College

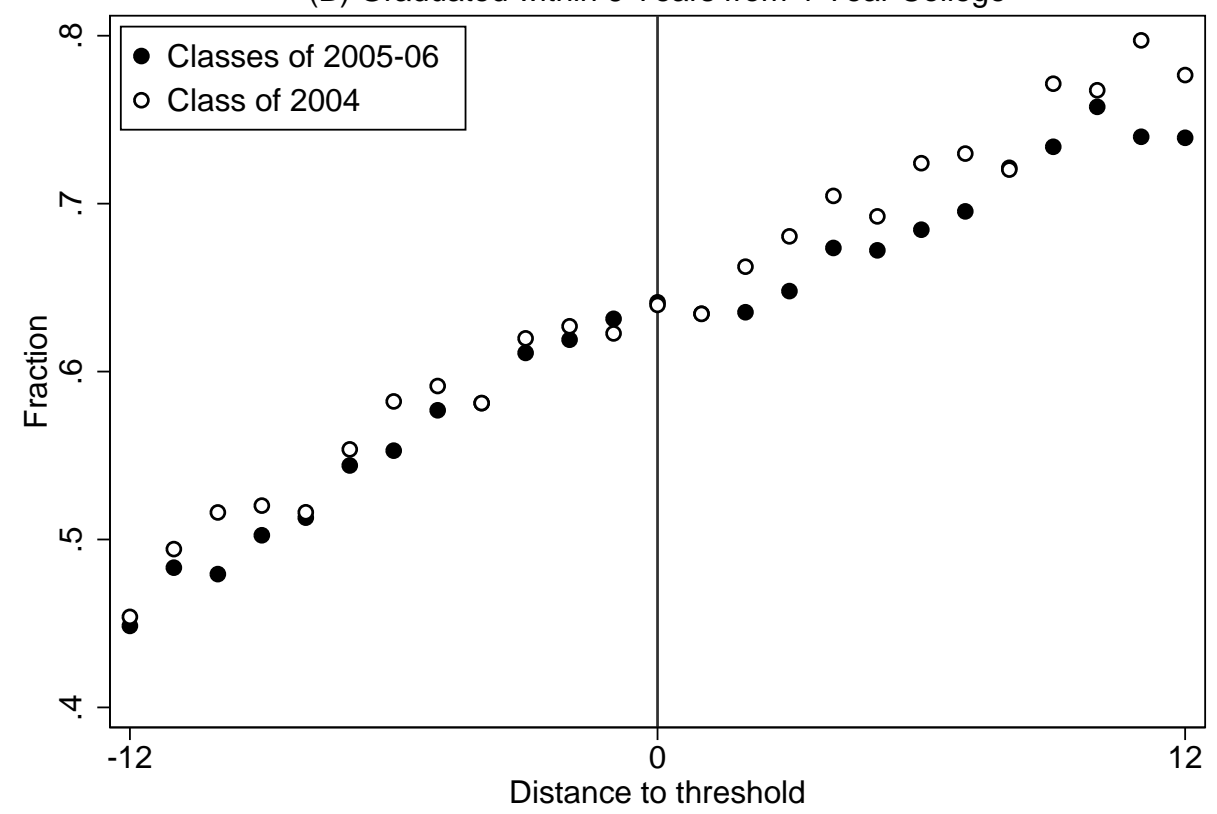

Notes: Panel A shows shows the fraction of students enrolling in a Massachusetts public four-year college immediately following high school graduation, for the treated high school classes of 200506 and the untreated class of 2004. Panel B shows the fraction of students graduating from any four-year college within six years of high school graduation. Calculations are based on National Student Clearinghouse data. 
Figure 8: Freshman Enrollment in Four-Year Adams Colleges

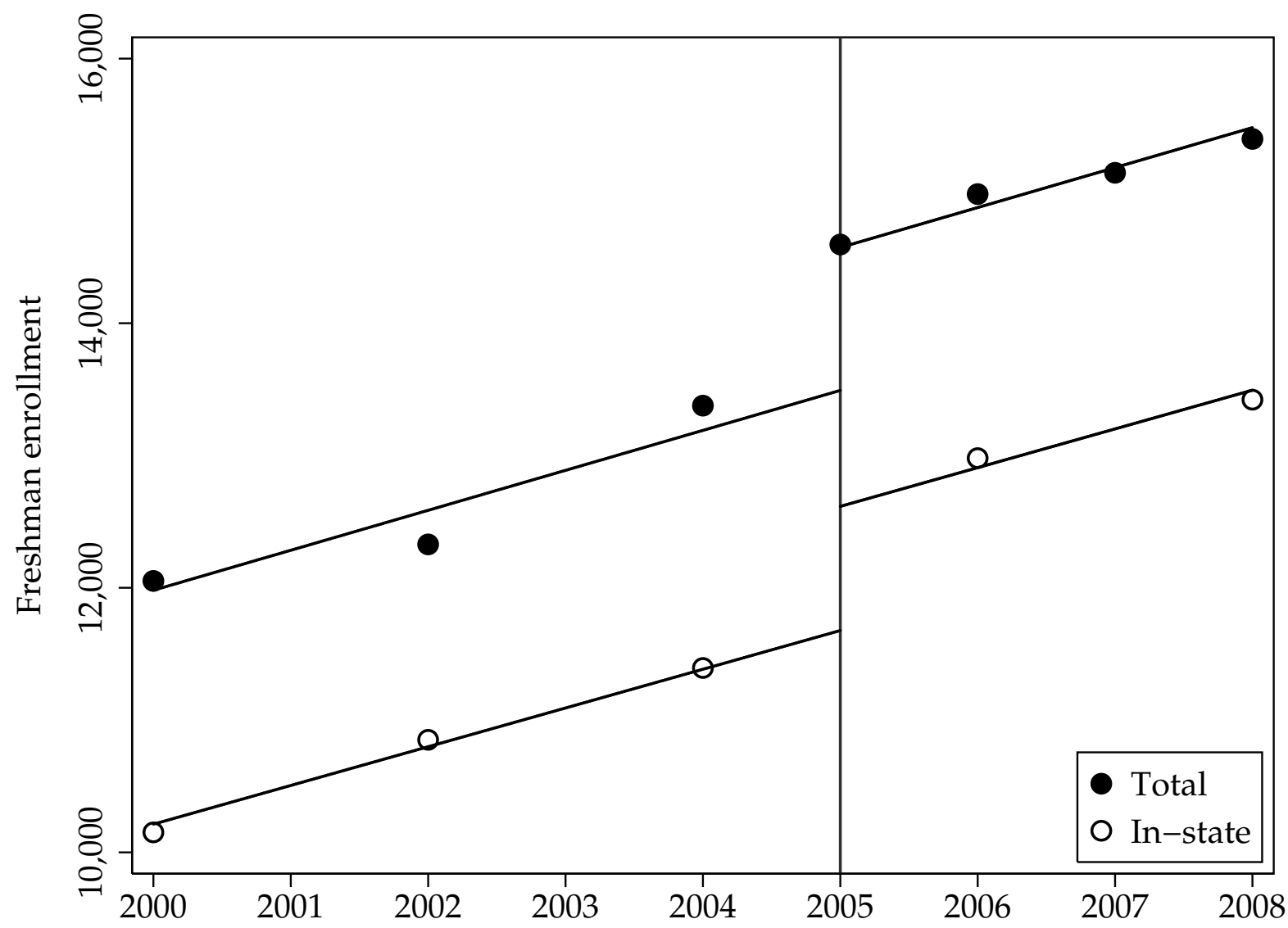

Notes: The above figure shows the total number of freshmen enrolled in Massachusetts public four-year colleges, as well as the number of such freshmen coming from Massachusetts. Calculations are based on IPEDS data. 
Table 1: Summary Statistics

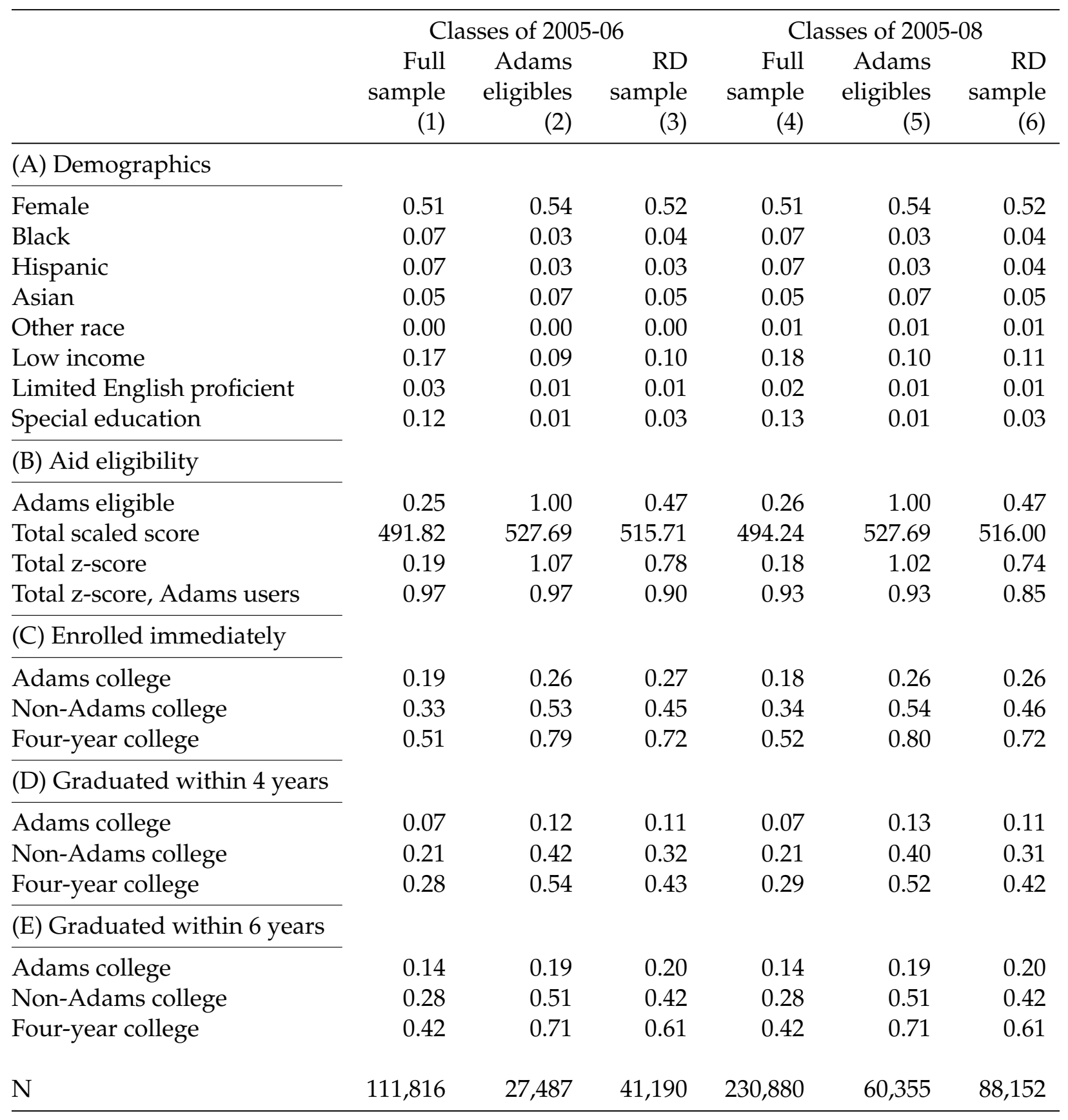

Notes: Mean values of each variable are shown by sample. Column (1) is the full sample of high school graduates from the classes of 2005-06. Column (2) restricts that sample to students eligible for the Adams Scholarship. Column (3) restricts the full sample to those within 12 points of the eligibility threshold. Columns (4)-(6) are defined similarly but for the high school classes of 2005-08. In panel (B), the last outcomes conditions on students using the Adams Scholarship to attend a four-year college. In panels (C)-(E), college outcomes all refer to four-year colleges. 
Table 2: Quality and Cost by Four-Year College Sector, Class of 2004

\begin{tabular}{lccc}
\hline & $\begin{array}{c}\text { Univ. of } \\
\text { Mass. } \\
(1)\end{array}$ & $\begin{array}{c}\text { State } \\
\text { college } \\
(2)\end{array}$ & $\begin{array}{c}\text { Non-Adams } \\
\text { college } \\
(3)\end{array}$ \\
\hline (A) Quality & & & \\
\hline Four-year graduation rate & 0.34 & 0.24 & 0.53 \\
SAT math 75th percentile & 610 & 550 & 619 \\
Instructional expenditures & 8,224 & 4,342 & 14,510 \\
College quality & -0.32 & -0.94 & 0.29 \\
(B) Costs & & & \\
Tuition & 1,438 & 850 & 19,588 \\
Required fees & 6,164 & 3,741 & 666 \\
Additional expenses & 7,004 & 6,635 & 8,614 \\
Total cost & 14,606 & 11,224 & 28,867 \\
Grant aid & 6,649 & 5,711 & 14,142 \\
Net price & 7,957 & 5,513 & 14,725 \\
Loans & 3,710 & 2,592 & 4,162 \\
N & & & 16,881 \\
\hline
\end{tabular}

Notes: Mean values of each variable are shown by sector for the first college of 2004 high school graduates who enroll on time in a four-year college. Quality and cost data are measured by IPEDS in the fall of 2004, with costs measured in 2004 dollars. 


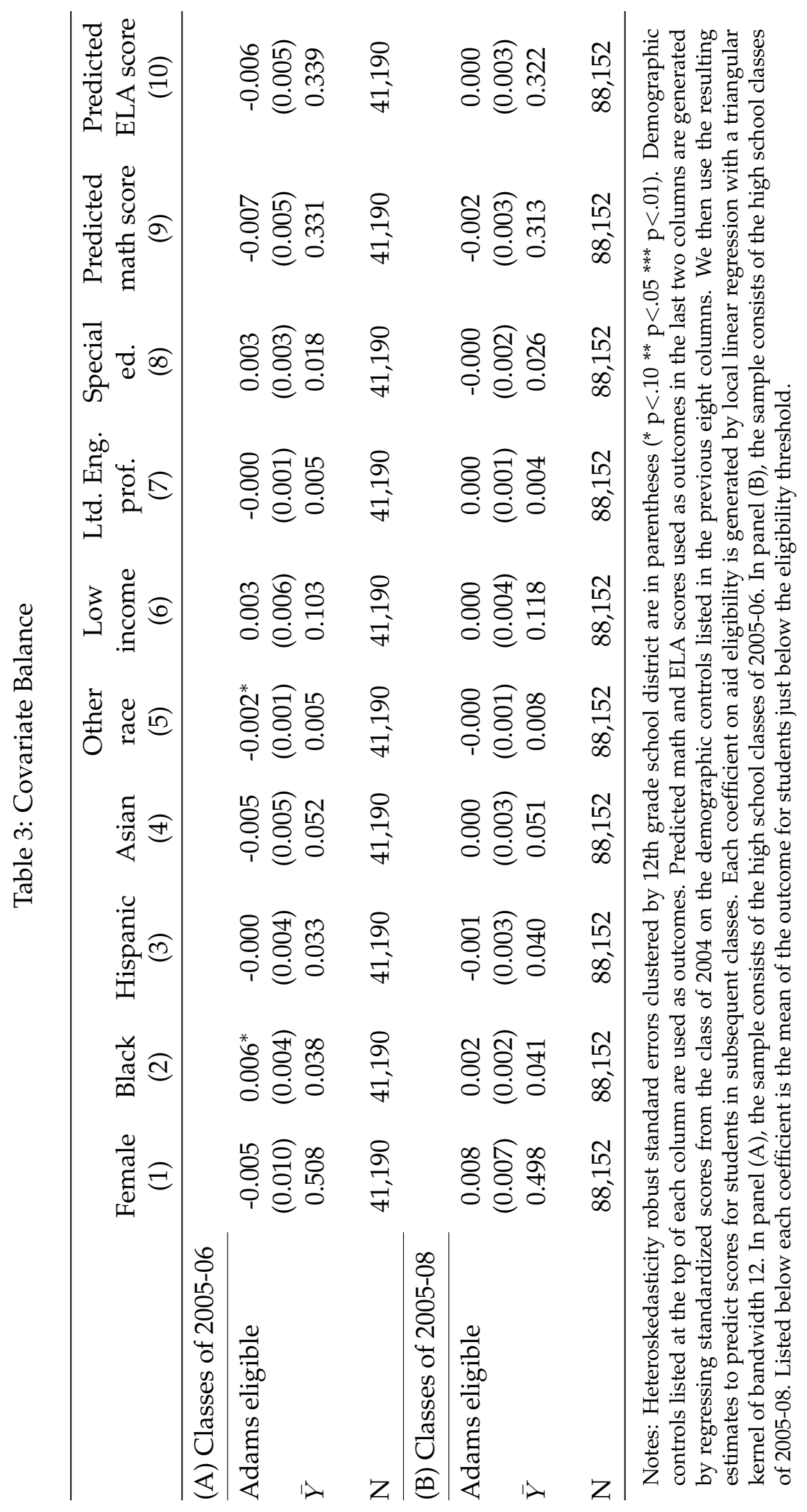




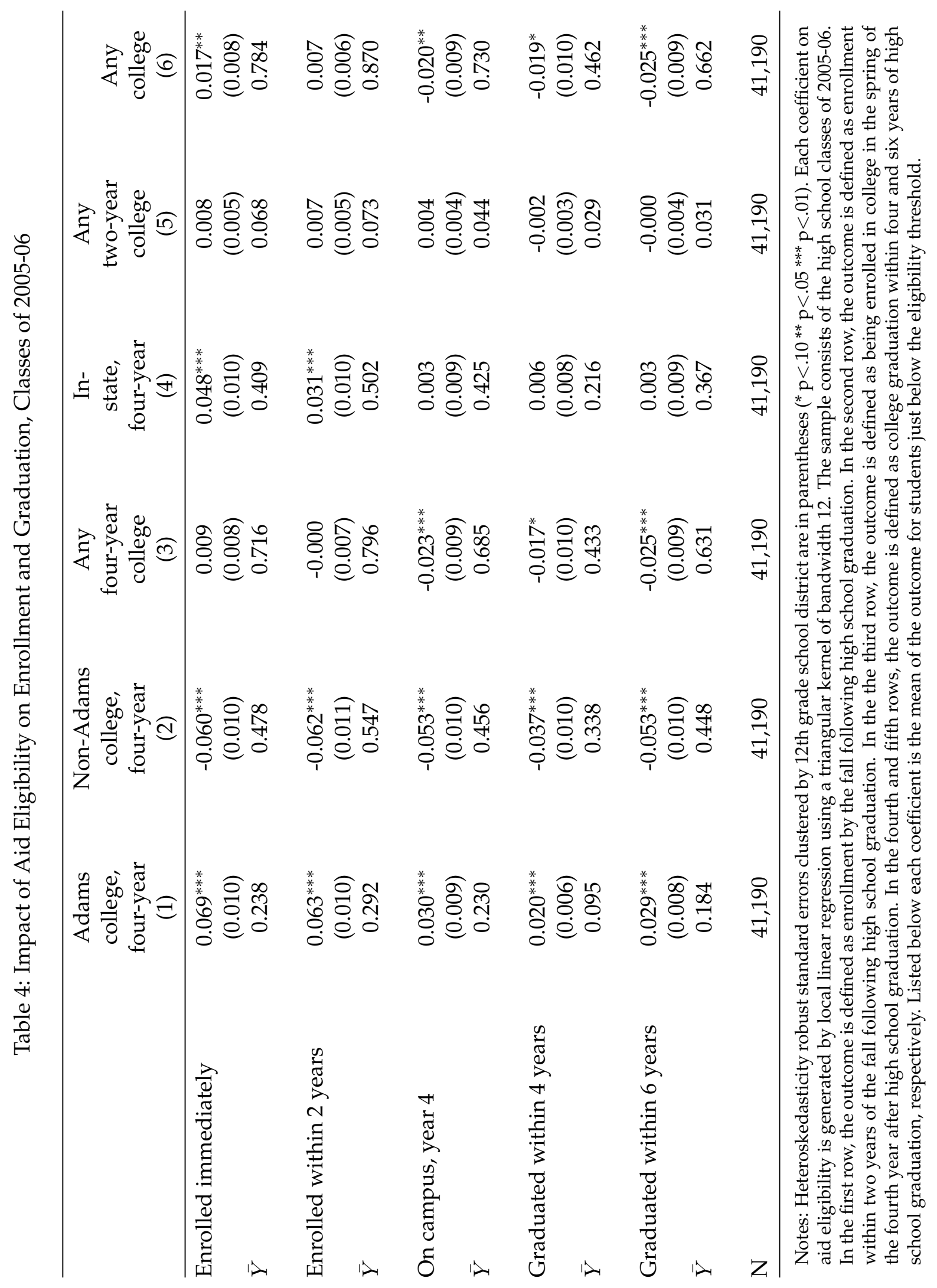


Table 5: Enrollment, Persistence and Graduation by High School Class

\begin{tabular}{|c|c|c|c|c|c|c|}
\hline & $\begin{array}{c}2005 \\
(1)\end{array}$ & $\begin{array}{c}2006 \\
(2)\end{array}$ & $\begin{array}{c}2007 \\
(3)\end{array}$ & $\begin{array}{c}2008 \\
(4)\end{array}$ & $\begin{array}{c}2005-08 \\
(5)\end{array}$ & $\begin{array}{c}2009-11 \\
\text { (6) }\end{array}$ \\
\hline \multicolumn{7}{|l|}{ (A) Enrolled } \\
\hline Immediately, Adams college & $\begin{array}{c}0.073^{* * *} \\
(0.016)\end{array}$ & $\begin{array}{c}0.067^{* * *} \\
(0.012)\end{array}$ & $\begin{array}{c}0.059^{* * *} \\
(0.013)\end{array}$ & $\begin{array}{c}0.046^{* * *} \\
(0.012)\end{array}$ & $\begin{array}{c}0.060^{* * *} \\
(0.007)\end{array}$ & $\begin{array}{c}0.020^{* * *} \\
(0.007)\end{array}$ \\
\hline $\bar{Y}$ & 0.234 & 0.242 & 0.223 & 0.241 & 0.235 & 0.234 \\
\hline Immediately, four-year college & $\begin{array}{c}0.029^{* *} \\
(0.014)\end{array}$ & $\begin{array}{l}-0.005 \\
(0.011)\end{array}$ & $\begin{array}{c}0.013 \\
(0.012)\end{array}$ & $\begin{array}{c}0.015 \\
(0.011)\end{array}$ & $\begin{array}{l}0.012^{* *} \\
(0.006)\end{array}$ & $\begin{array}{l}-0.006 \\
(0.007)\end{array}$ \\
\hline $\bar{Y}$ & 0.692 & 0.733 & 0.730 & 0.716 & 0.719 & 0.713 \\
\hline Within 2 years, four-year college & $\begin{array}{c}0.017 \\
(0.012)\end{array}$ & $\begin{array}{l}-0.014 \\
(0.009)\end{array}$ & $\begin{array}{l}-0.000 \\
(0.012)\end{array}$ & $\begin{array}{c}0.004 \\
(0.010)\end{array}$ & $\begin{array}{c}0.001 \\
(0.005)\end{array}$ & $\begin{array}{l}-0.009 \\
(0.006)\end{array}$ \\
\hline $\bar{Y}$ & 0.770 & 0.816 & 0.787 & 0.775 & 0.788 & 0.762 \\
\hline \multicolumn{7}{|l|}{ (B) Graduated } \\
\hline On campus, year 4 & $\begin{array}{l}-0.003 \\
(0.016)\end{array}$ & $\begin{array}{c}-0.039^{* * *} \\
(0.011)\end{array}$ & $\begin{array}{c}-0.018 \\
(0.014)\end{array}$ & $\begin{array}{c}-0.008 \\
(0.011)\end{array}$ & $\begin{array}{c}-0.017^{* * *} \\
(0.006)\end{array}$ & \\
\hline $\bar{Y}$ & 0.679 & 0.690 & 0.631 & 0.620 & 0.653 & \\
\hline Within 4 years & $\begin{array}{c}-0.017 \\
(0.016)\end{array}$ & $\begin{array}{l}-0.018 \\
(0.013)\end{array}$ & $\begin{array}{c}-0.008 \\
(0.014)\end{array}$ & $\begin{array}{c}-0.002 \\
(0.013)\end{array}$ & $\begin{array}{l}-0.010 \\
(0.007)\end{array}$ & \\
\hline $\bar{Y}$ & 0.418 & 0.444 & 0.411 & 0.420 & 0.424 & \\
\hline Within 5 years & $\begin{array}{l}-0.018 \\
(0.016)\end{array}$ & $\begin{array}{c}-0.034^{* * *} \\
(0.013)\end{array}$ & $\begin{array}{c}-0.016 \\
(0.014)\end{array}$ & & $\begin{array}{c}-0.023^{* * *} \\
(0.008)\end{array}$ & \\
\hline $\bar{Y}$ & 0.570 & 0.595 & 0.562 & & 0.576 & \\
\hline Within 6 years & $\begin{array}{c}-0.024 \\
(0.015)\end{array}$ & $\begin{array}{c}-0.026^{* *} \\
(0.012)\end{array}$ & & & $\begin{array}{c}-0.025^{* * *} \\
(0.009)\end{array}$ & \\
\hline $\bar{Y}$ & 0.630 & 0.632 & & & 0.631 & \\
\hline $\mathrm{N}$ & 18,270 & 22,920 & 21,808 & 25,154 & 88,152 & 74,139 \\
\hline
\end{tabular}

Notes: Heteroskedasticity robust standard errors clustered by 12 th grade school district are in parentheses $\left({ }^{*} \mathrm{p}<.10\right.$ ${ }^{* *} \mathrm{p}<.05^{* * *} \mathrm{p}<.01$ ). Each coefficient on aid eligibility is generated by local linear regression using a triangular kernel of bandwidth 12. Each column consists of a different high school class or set of classes. In panel (A), the outcomes are defined as enrollment immediately or within two years of high school graduation. In panel (B), the outcomes are defined as being on campus or graduating from any four-year college, regardless of initial enrollment choice. Listed below each coefficient is the mean of the outcome for students just below the eligibility threshold. 


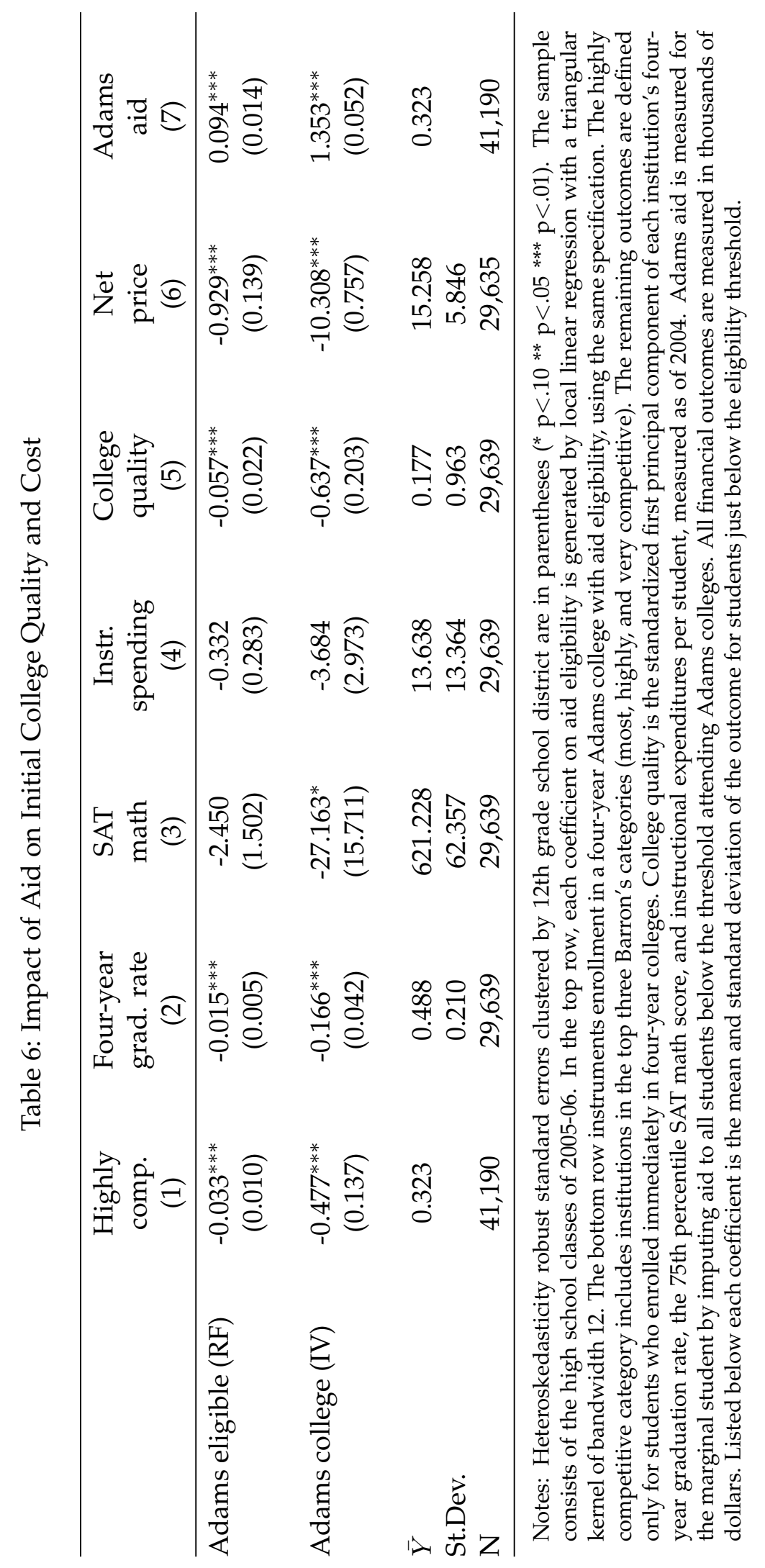


Table 7: Heterogeneity by Student Characteristics

\begin{tabular}{|c|c|c|c|c|c|}
\hline & $\begin{array}{c}\text { Enrolled } \\
\text { immediately, } \\
\text { Adams } \\
\text { college } \\
(1)\end{array}$ & $\begin{array}{c}\text { Enrolled } \\
\text { immediately, } \\
\text { four-year } \\
\text { college } \\
(2)\end{array}$ & $\begin{array}{c}\text { Enrolled } \\
\text { immediately, } \\
\text { highly } \\
\text { competitive } \\
\text { (3) }\end{array}$ & $\begin{array}{c}\text { On campus } \\
\text { in year } 4, \\
\text { four-year } \\
\text { college } \\
(4)\end{array}$ & $\begin{array}{c}\text { Graduatec } \\
\text { within 4, } \\
\text { four-year } \\
\text { college } \\
\text { (5) }\end{array}$ \\
\hline \multicolumn{6}{|l|}{ (A) By district selectivity } \\
\hline Eligible * bottom quintile & $\begin{array}{c}0.077^{* * *} \\
(0.016)\end{array}$ & $\begin{array}{c}0.050^{* * *} \\
(0.011)\end{array}$ & $\begin{array}{l}0.014^{*} \\
(0.007)\end{array}$ & $\begin{array}{c}0.010 \\
(0.012)\end{array}$ & $\begin{array}{c}0.010 \\
(0.012)\end{array}$ \\
\hline Eligible ${ }^{*}$ middle quintiles & $\begin{array}{c}0.068^{* * *} \\
(0.009)\end{array}$ & $\begin{array}{c}0.011 \\
(0.008)\end{array}$ & $\begin{array}{c}-0.026^{* * *} \\
(0.008)\end{array}$ & $\begin{array}{c}-0.026^{* * *} \\
(0.008)\end{array}$ & $\begin{array}{c}-0.018^{* *} \\
(0.009)\end{array}$ \\
\hline Eligible ${ }^{*}$ top quintile & $\begin{array}{c}0.015 \\
(0.009)\end{array}$ & $\begin{array}{c}0.004 \\
(0.008)\end{array}$ & $\begin{array}{l}-0.009 \\
(0.014)\end{array}$ & $\begin{array}{c}0.004 \\
(0.011)\end{array}$ & $\begin{array}{c}0.017 \\
(0.012)\end{array}$ \\
\hline $\begin{array}{l}\mathrm{p}(\text { Bottom }=\text { Middle }) \\
\mathrm{p}(\text { Top }=\text { Middle })\end{array}$ & $\begin{array}{l}0.609 \\
0.000\end{array}$ & $\begin{array}{l}0.005 \\
0.558\end{array}$ & $\begin{array}{l}0.000 \\
0.276\end{array}$ & $\begin{array}{l}0.016 \\
0.027\end{array}$ & $\begin{array}{l}0.066 \\
0.022\end{array}$ \\
\hline \multicolumn{6}{|l|}{ (B) By race/ethnicity } \\
\hline Eligible * white & $\begin{array}{c}0.054^{* * *} \\
(0.007)\end{array}$ & $\begin{array}{c}0.008 \\
(0.006)\end{array}$ & $\begin{array}{c}-0.026^{* * *} \\
(0.007)\end{array}$ & $\begin{array}{c}-0.020^{* * *} \\
(0.006)\end{array}$ & $\begin{array}{l}-0.009 \\
(0.007)\end{array}$ \\
\hline Eligible ${ }^{*}$ non-white & $\begin{array}{c}0.133^{* * *} \\
(0.019)\end{array}$ & $\begin{array}{c}0.063^{* * *} \\
(0.019)\end{array}$ & $\begin{array}{c}0.005 \\
(0.016)\end{array}$ & $\begin{array}{c}0.019 \\
(0.021)\end{array}$ & $\begin{array}{l}-0.024 \\
(0.019)\end{array}$ \\
\hline $\mathrm{p}$ (White $=$ Non-white $)$ & 0.000 & 0.007 & 0.079 & 0.069 & 0.480 \\
\hline \multicolumn{6}{|l|}{ (C) By poverty status } \\
\hline Eligible ${ }^{*}$ nonpoor & $\begin{array}{c}0.055^{* * *} \\
(0.007)\end{array}$ & $\begin{array}{c}0.009 \\
(0.006)\end{array}$ & $\begin{array}{c}-0.027^{* * *} \\
(0.008)\end{array}$ & $\begin{array}{c}-0.016^{* *} \\
(0.006)\end{array}$ & $\begin{array}{l}-0.010 \\
(0.007)\end{array}$ \\
\hline Eligible ${ }^{*}$ poor & $\begin{array}{c}0.105^{* * *} \\
(0.017)\end{array}$ & $\begin{array}{l}0.037^{* *} \\
(0.017)\end{array}$ & $\begin{array}{c}0.003 \\
(0.011)\end{array}$ & $\begin{array}{l}-0.030 \\
(0.018)\end{array}$ & $\begin{array}{l}-0.015 \\
(0.015)\end{array}$ \\
\hline $\mathrm{p}($ Poor $=$ Non-poor $)$ & 0.006 & 0.126 & 0.024 & 0.452 & 0.769 \\
\hline \multicolumn{6}{|l|}{ (D) By gender } \\
\hline Eligible* male & $\begin{array}{c}0.053^{* * *} \\
(0.009)\end{array}$ & $\begin{array}{c}0.011 \\
(0.008)\end{array}$ & $\begin{array}{c}-0.030^{* * *} \\
(0.009)\end{array}$ & $\begin{array}{l}-0.009 \\
(0.009)\end{array}$ & $\begin{array}{l}-0.008 \\
(0.009)\end{array}$ \\
\hline Eligible ${ }^{*}$ female & $\begin{array}{c}0.067^{* * *} \\
(0.009)\end{array}$ & $\begin{array}{c}0.011 \\
(0.008)\end{array}$ & $\begin{array}{l}-0.017^{*} \\
(0.009)\end{array}$ & $\begin{array}{c}-0.026^{* * *} \\
(0.009)\end{array}$ & $\begin{array}{l}-0.014 \\
(0.010)\end{array}$ \\
\hline $\mathrm{p}($ Male $=$ Female $)$ & 0.258 & 0.958 & 0.303 & 0.159 & 0.679 \\
\hline $\mathrm{N}$ & 88,152 & 88,152 & 88,152 & 88,152 & 88,152 \\
\hline
\end{tabular}

Notes: Heteroskedasticity robust standard errors clustered by distance from the threshold are in parentheses $\left(^{*}\right.$ $\mathrm{p}<.10^{* *} \mathrm{p}<.05^{* * *} \mathrm{p}<.01$ ). The sample consists of the high school classes of 2005-08. Each panel's baseline specification uses local linear regression with a triangular kernel of bandwidth 12 . Each panel then fully interacts that baseline specification with indicators for the given categories. Panel (A) divides school districts into quintiles by the fraction of 2004 graduates who enrolled in colleges defined by Barron's as highly competitive. Panel (B) divides students into white and non-white, the latter defined by being black or Hispanic. Panel (C) divides students into non-poor and poor, the latter defined by receipt of free or reduced price lunch status. Panel (D) divides students by gender. Below each panel is the p-value from a test of the equality of the two listed coefficients. 


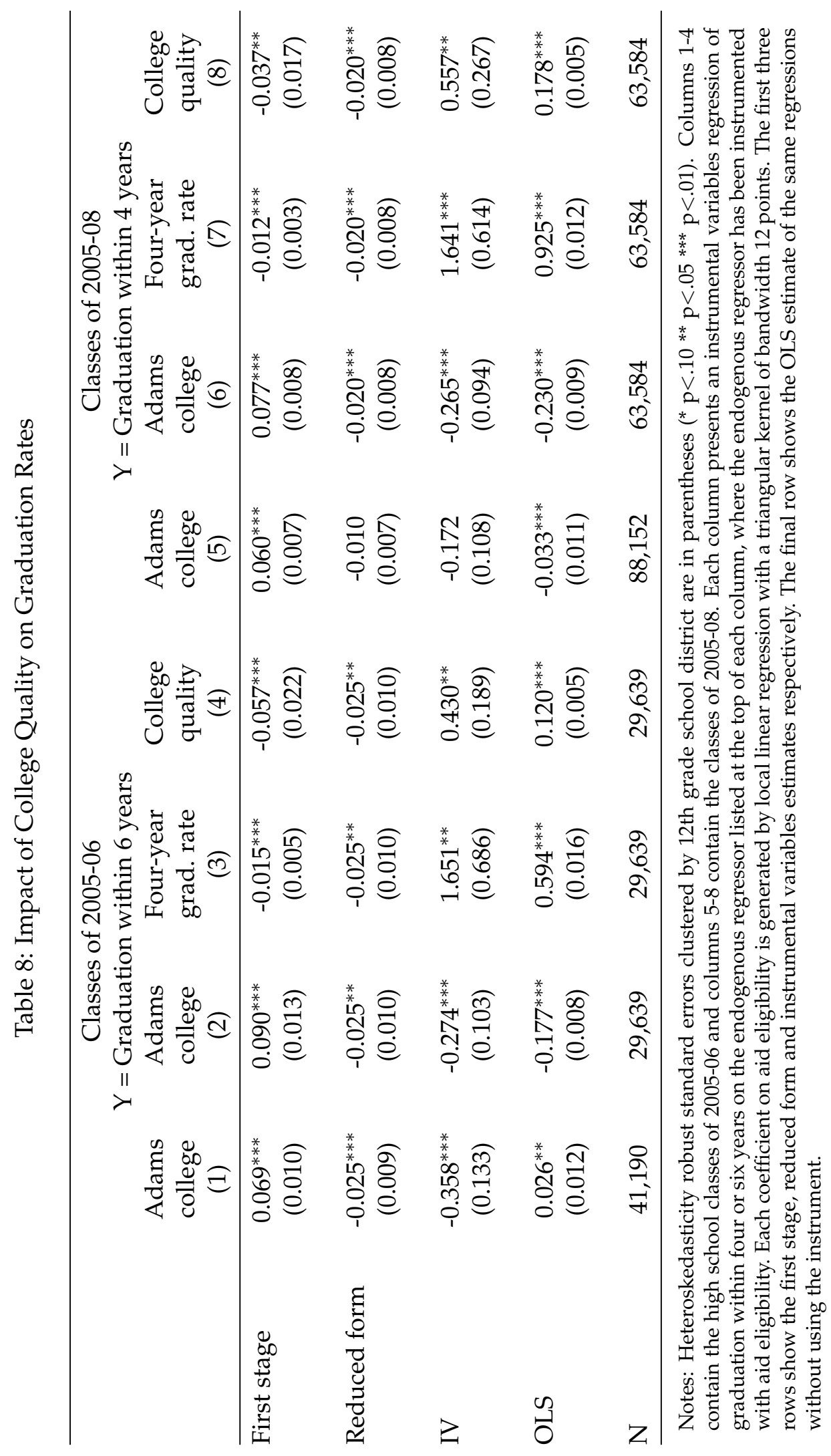


Figure A.1: Award Letter to Class of 2005



Notes: Above is a copy of the Adams Scholarship award letter sent to the first treated cohort, high school seniors in the class of 2005. 
Figure A.2: Award Letter to Class of 2006

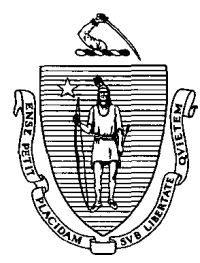

\section{The Commonwealth of Massachusetts \\ Executive Department \\ STATE HOUSE - BOSTON 02133}

(617) $725-4000$

MITT ROMNEY

GOVERNOR

KERRY HEALEY

LIEUTENANT GOVERNOR

December 9, 2005

Dear

Congratulations! You are a recipient of the John and Abigail Adams Scholarship. The Adams scholarship offers four years of free tuition to full-time students attending any University of Massachusetts campus, or any state or community college, beginning with the fall 2006 semester. Your outstanding MCAS results have qualified you to receive this award.

We created this merit scholarship program to reward your hard work and achievement. With the support of the Board of Higher Education, the Class of 2006 is now the second class to be awarded this opportunity. It is the strongest expression we can make of our commitment to attracting students like you — the best and brightest in the state — to our Commonwealth's public higher education system.

I encourage you to read the enclosed material and apply to any of the campuses on the attached list. Please present a copy of this letter once you are accepted to the college of your choice as proof of your award. College fees and rooming costs are not included in this scholarship award, so it is in your interest to complete the Free Application for Federal Student Aid (FAFSA) to help with these costs.

Congratulations again, and best wishes for your continued success.

Sincerely,

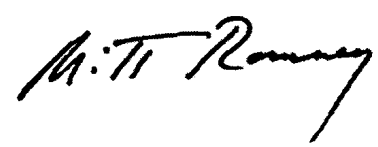

Mitt Romney

Notes: Above is a copy of the Adams Scholarship award letter sent to the second treated cohort, high school seniors in the class of 2006. 
Figure A.3: Award Letter to Class of 2012

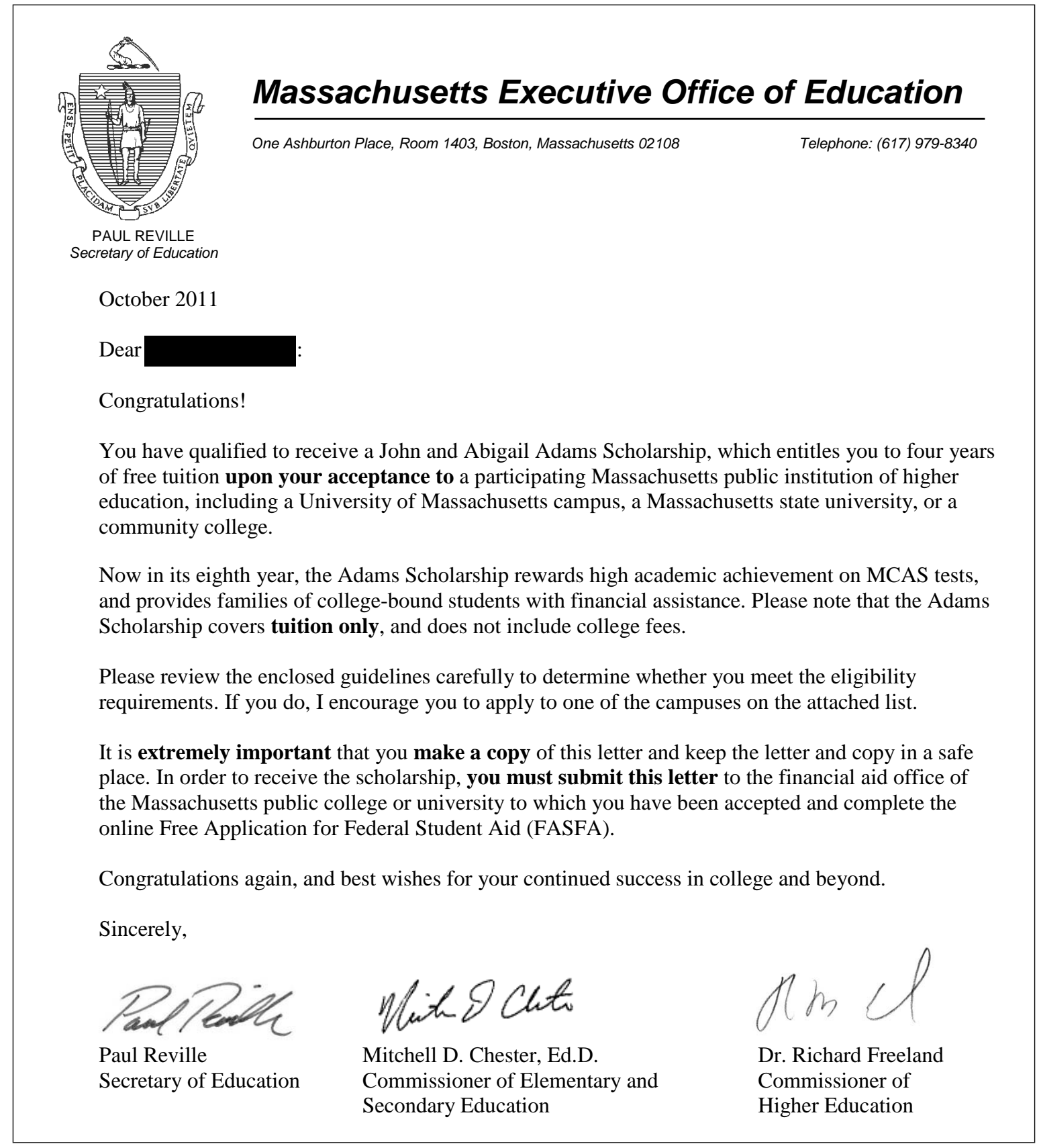

Notes: Above is a copy of the Adams Scholarship award letter sent to a recently treated cohort, high school seniors in the class of 2012. 
Figure A.4: Tuition and Fees at Two Typical Adams Colleges
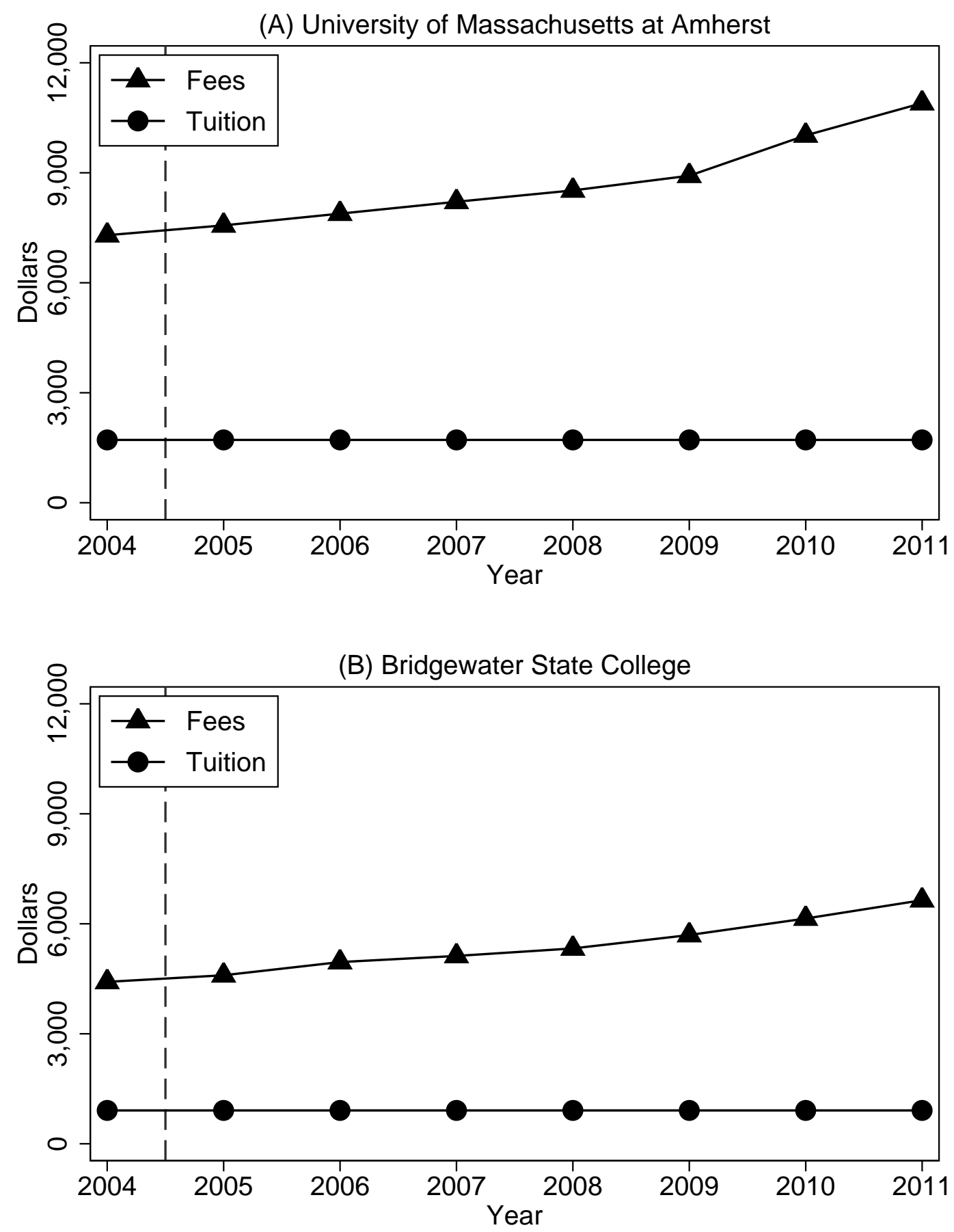

Notes: The above panels show tuition and fees over time for the largest U. Mass. campus and the largest state college. Data come from http://www. mass.edu/campuses/tuitionfees.asp. accessed on May 28, 2013. 
Figure A.5: Adams Eligibility by High School Class

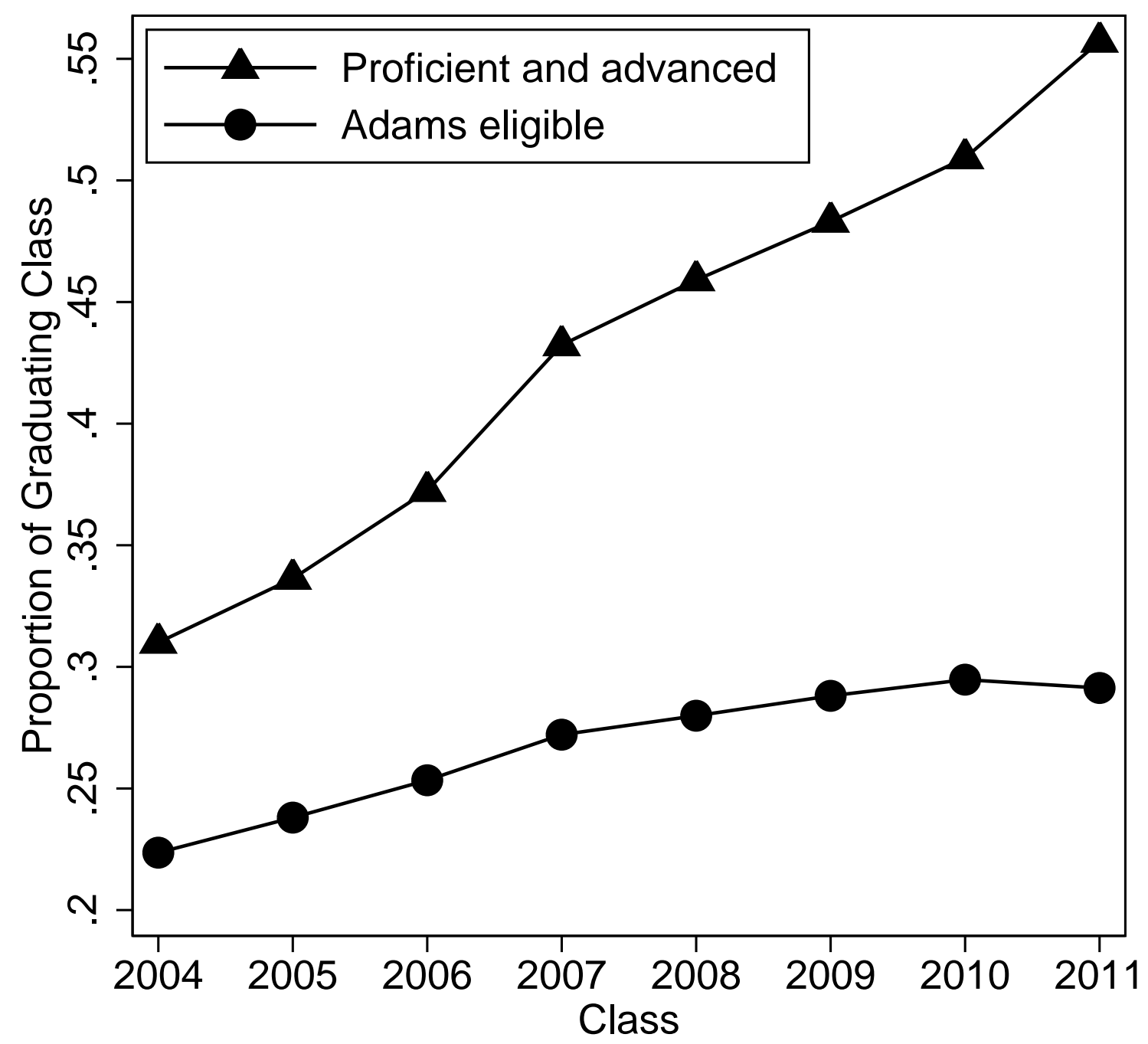

Notes: The top line shows the fraction of students scoring advanced on one MCAS section and proficient or advanced on the other. The bottom line shows the fraction of students deemed eligible for the Adams Scholarship. Calculations are based on data from DESE. 


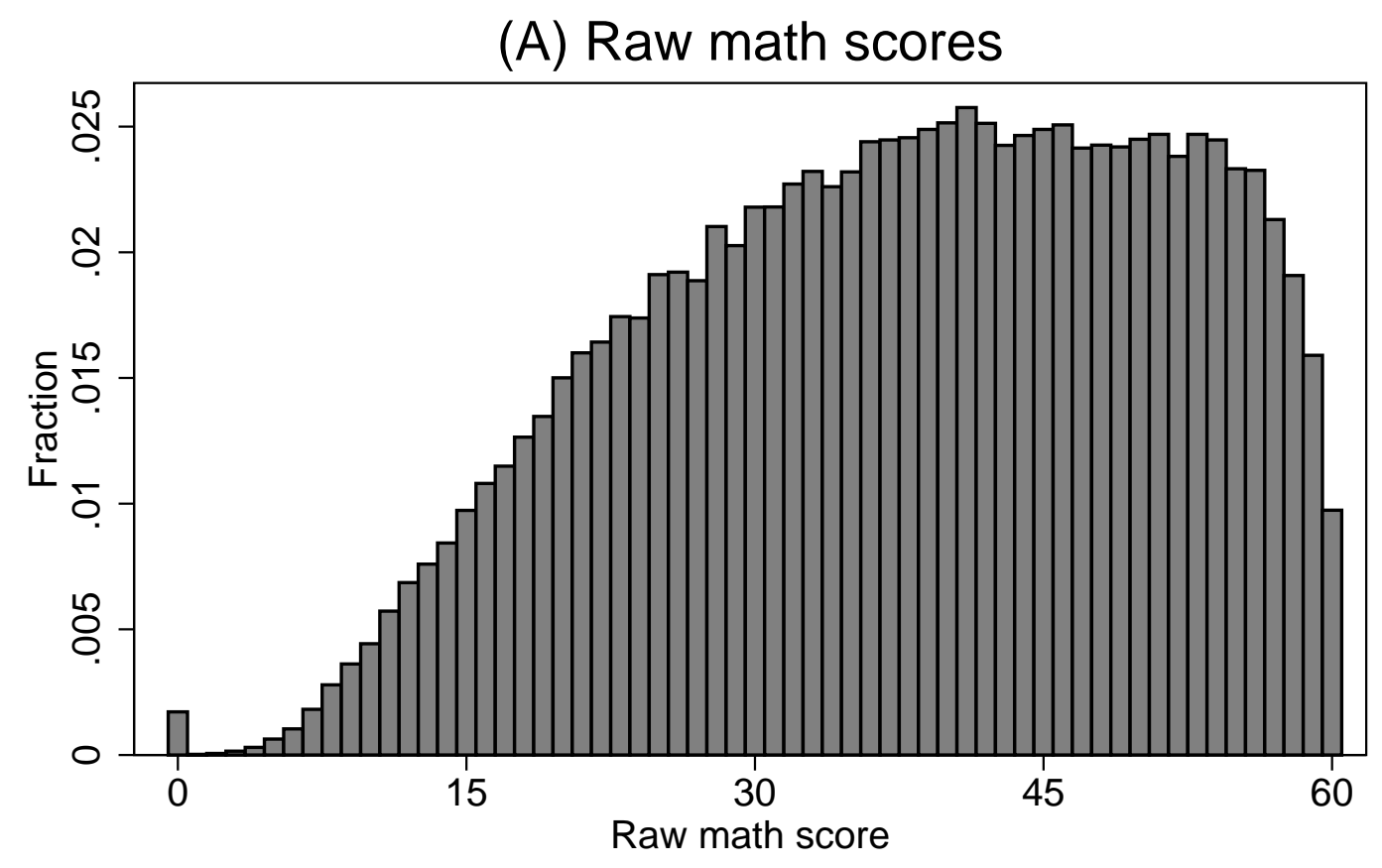

(B) Raw ELA scores

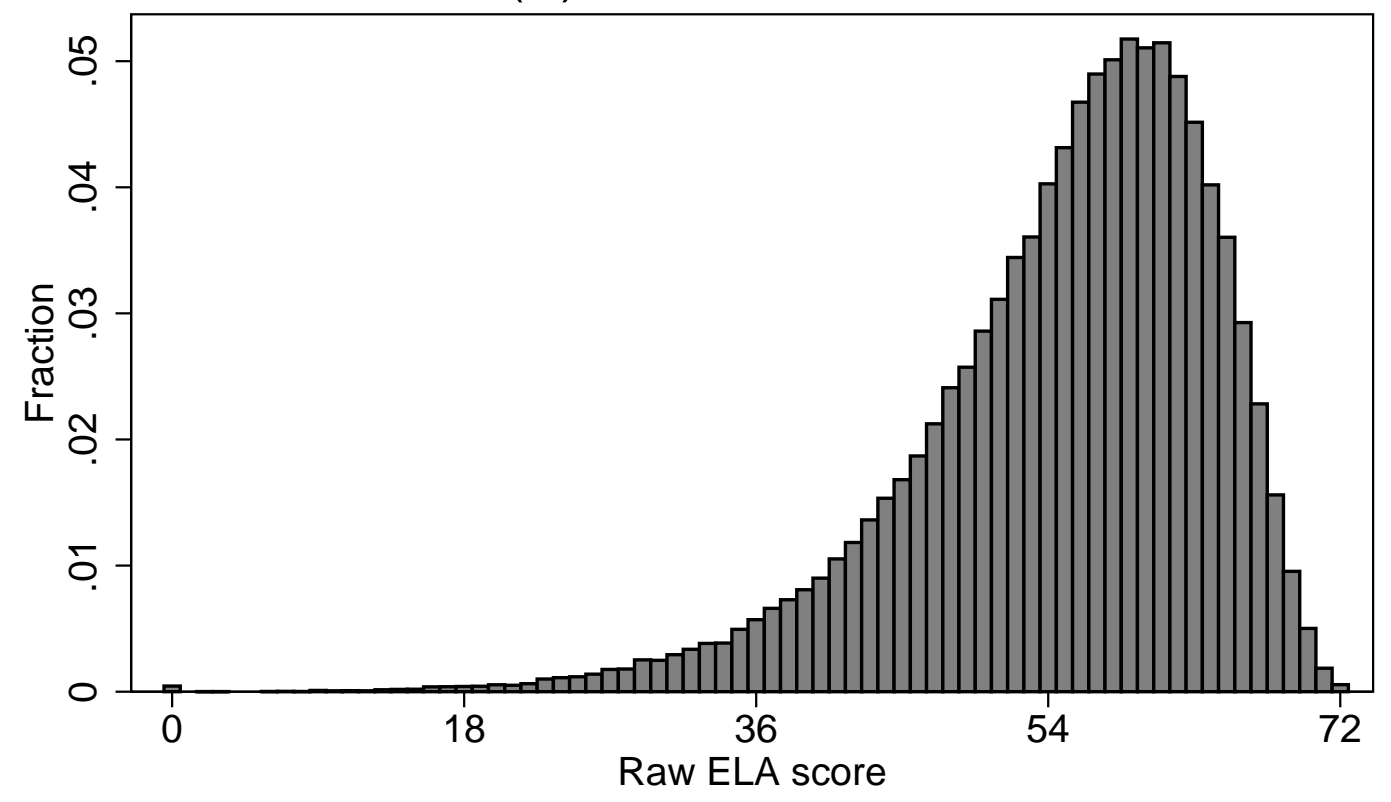

Notes: The above panels show, for the high school classes of 2005-06, the full distribution of raw math and ELA MCAS scores that underlie construction of the running variable. Calculations are based on data from DESE. 
Figure A.7: Density of Raw Scores, Classes of 2005-08

\section{(A) Raw math scores}

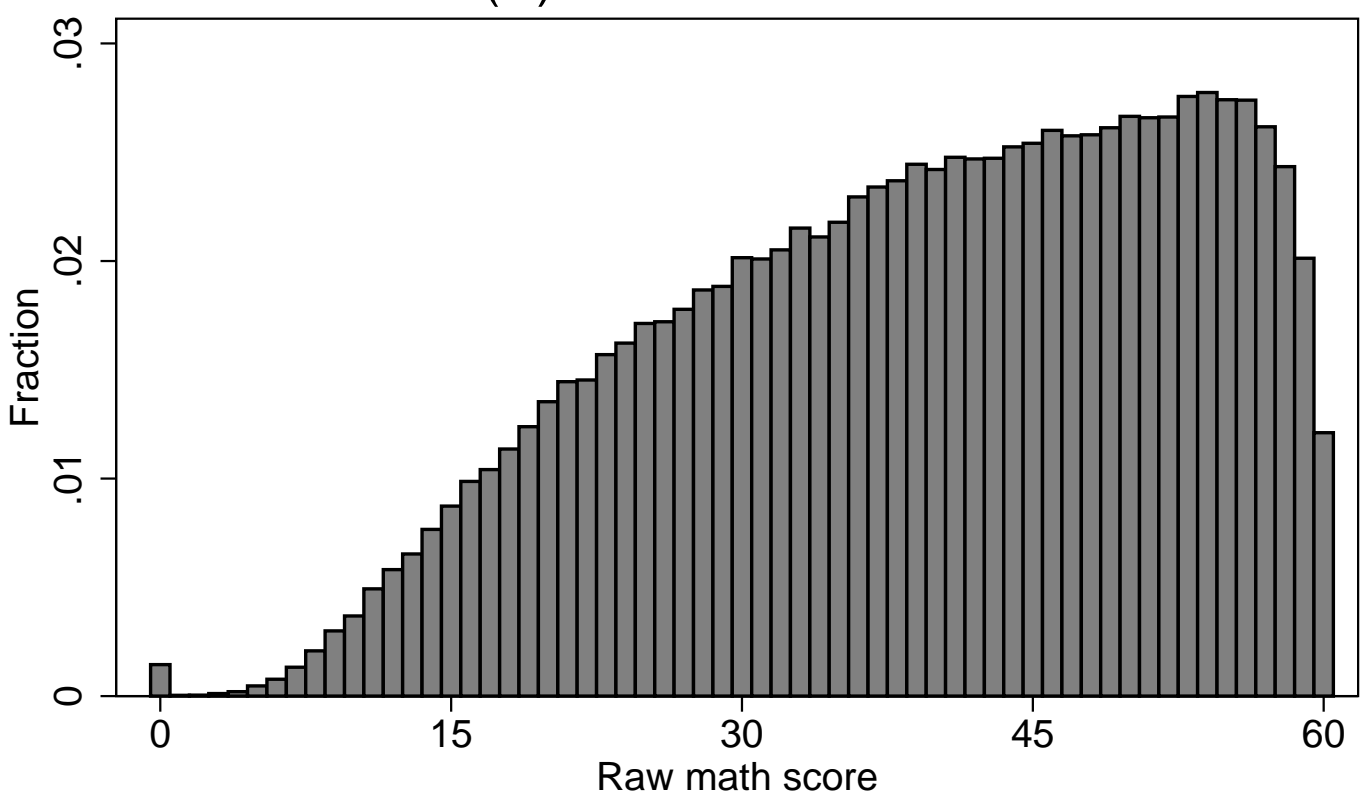

(B) Raw ELA scores



Notes: The above panels show, for the high school classes of 2005-08, the full distribution of raw math and ELA MCAS scores that underlie construction of the running variable. Calculations are based on data from DESE. 
Figure A.8: Density of the Running Variable in Proficient/Advanced Districts, Classes of 2005-06

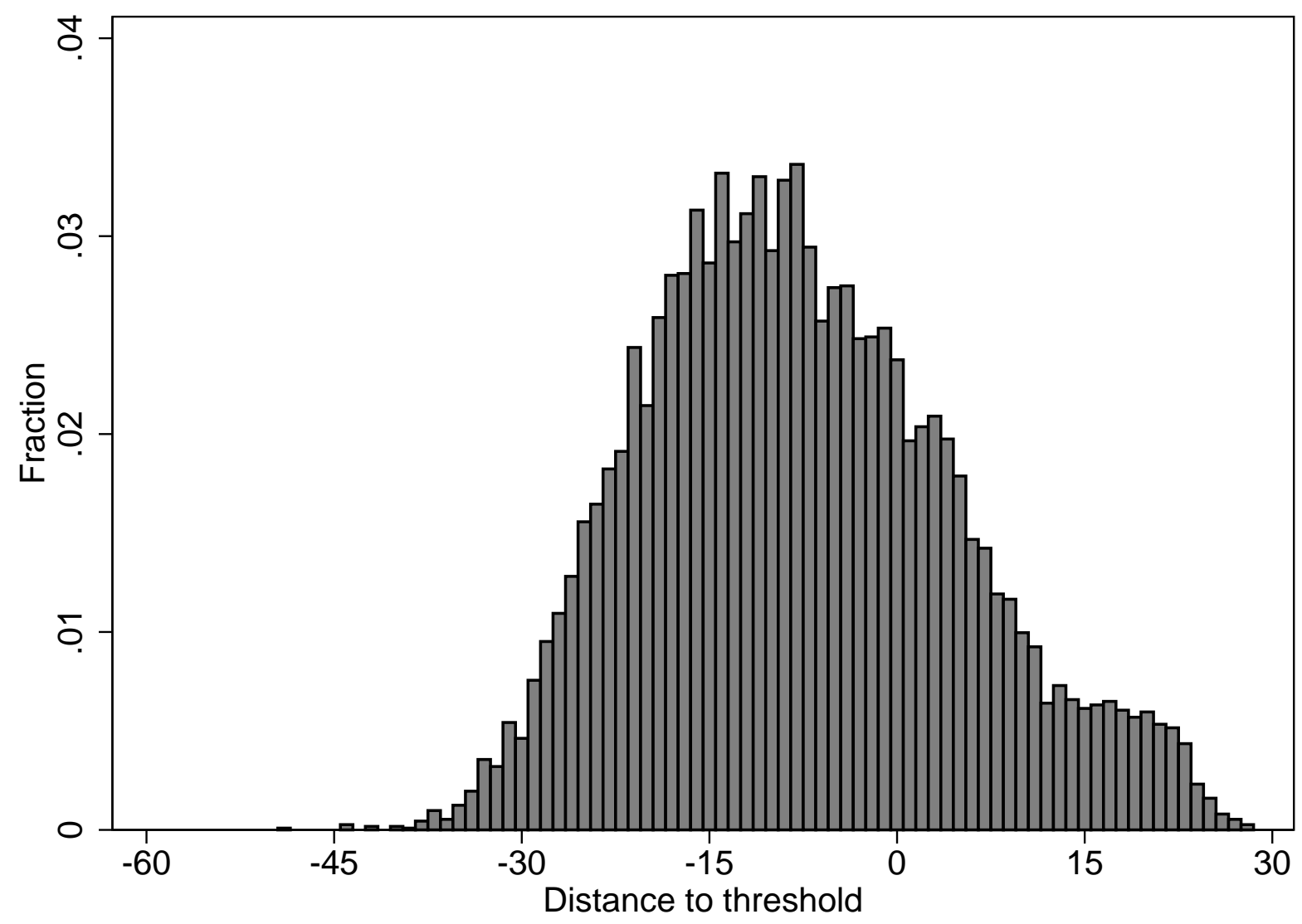

Notes: The above figure shows, for the high school classes of 2005-06, the full distribution of the running variable in school districts where the proficient/advanced threshold is binding and the top $25 \%$ threshold is irrelevant. Calculations are based on data from DESE. 
Figure A.9: Density of the Running Variable, Classes of 2005-08
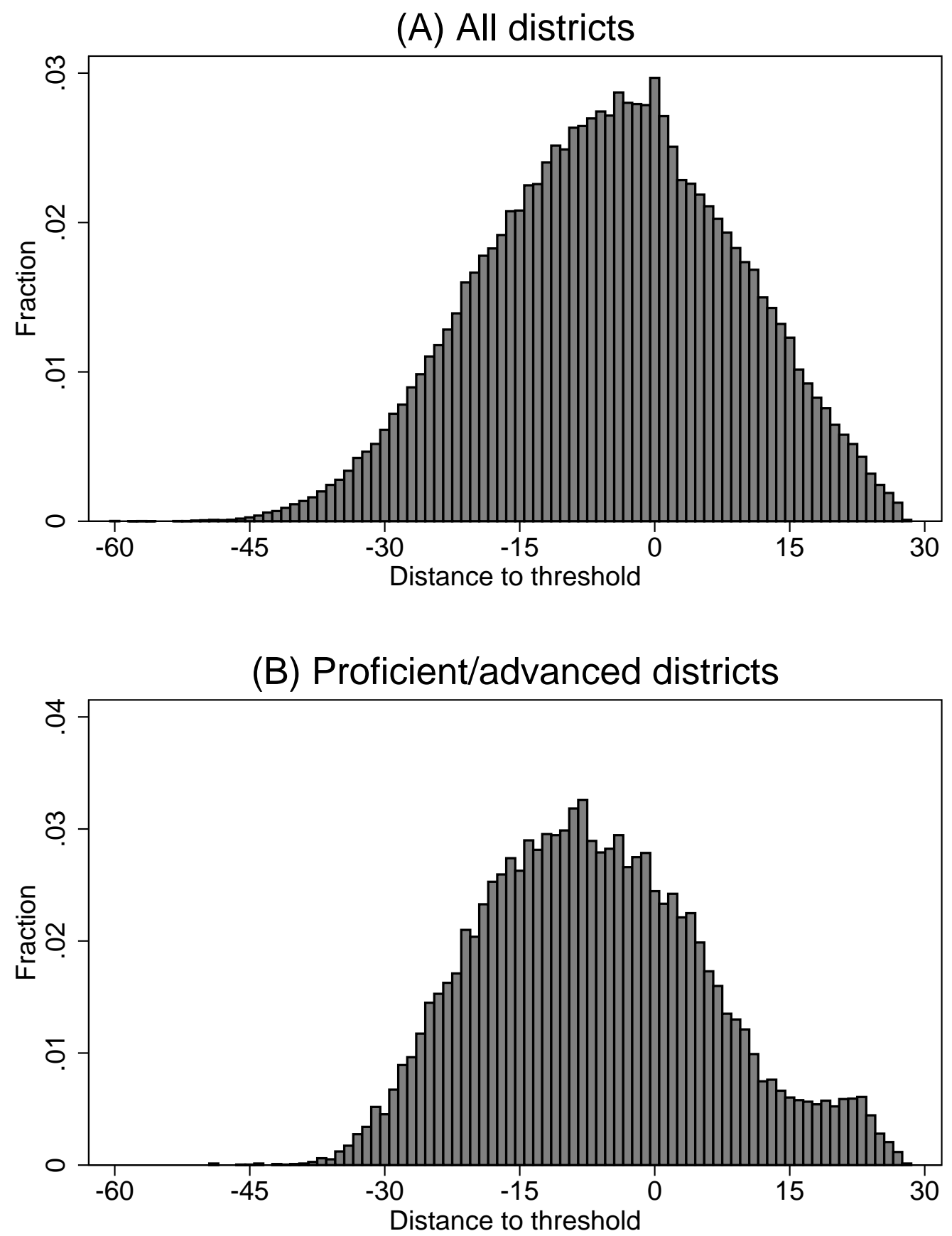

Notes: Panel A shows, for the high school classes of 2005-08, the full distribution of the running variable in all school districts. Panel B shows the distribution of the running variable in districts where the proficient/advanced threshold is binding and the top $25 \%$ threshold is irrelevant. Calculations are based on data from DESE. 
(A) Predicted math score, 2005-08



(B) Predicted ELA score, 2005-08

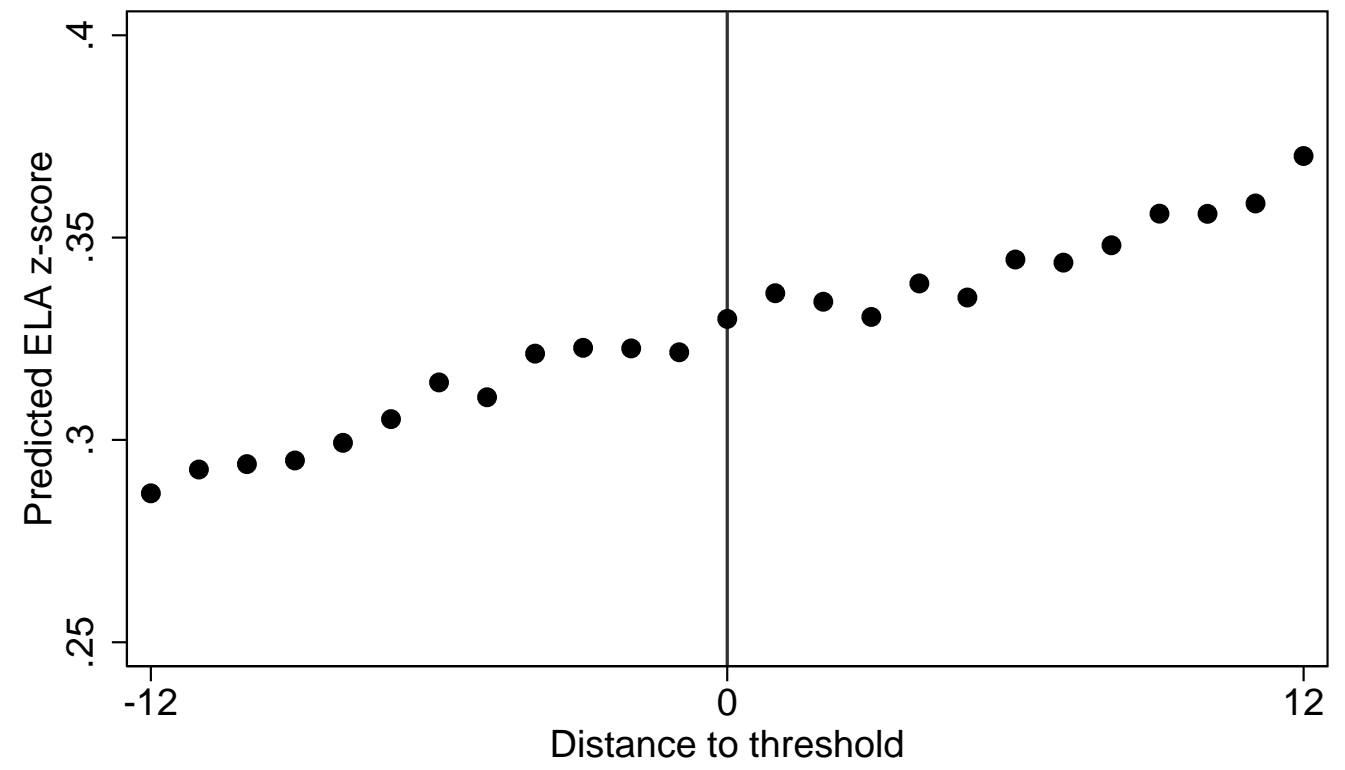

Notes: Each panel shows the mean predicted math and ELA score by each value of the running variable, for the high school classes of 2005-08. Predicted scores are generated by regressing math and ELA scores on demographic characteristics for the class of 2004. The resulting coefficients are then used to generate predictions for subsequent classes. 
Figure A.11: Enrollment at Four-Year Colleges, Classes of 2005-08

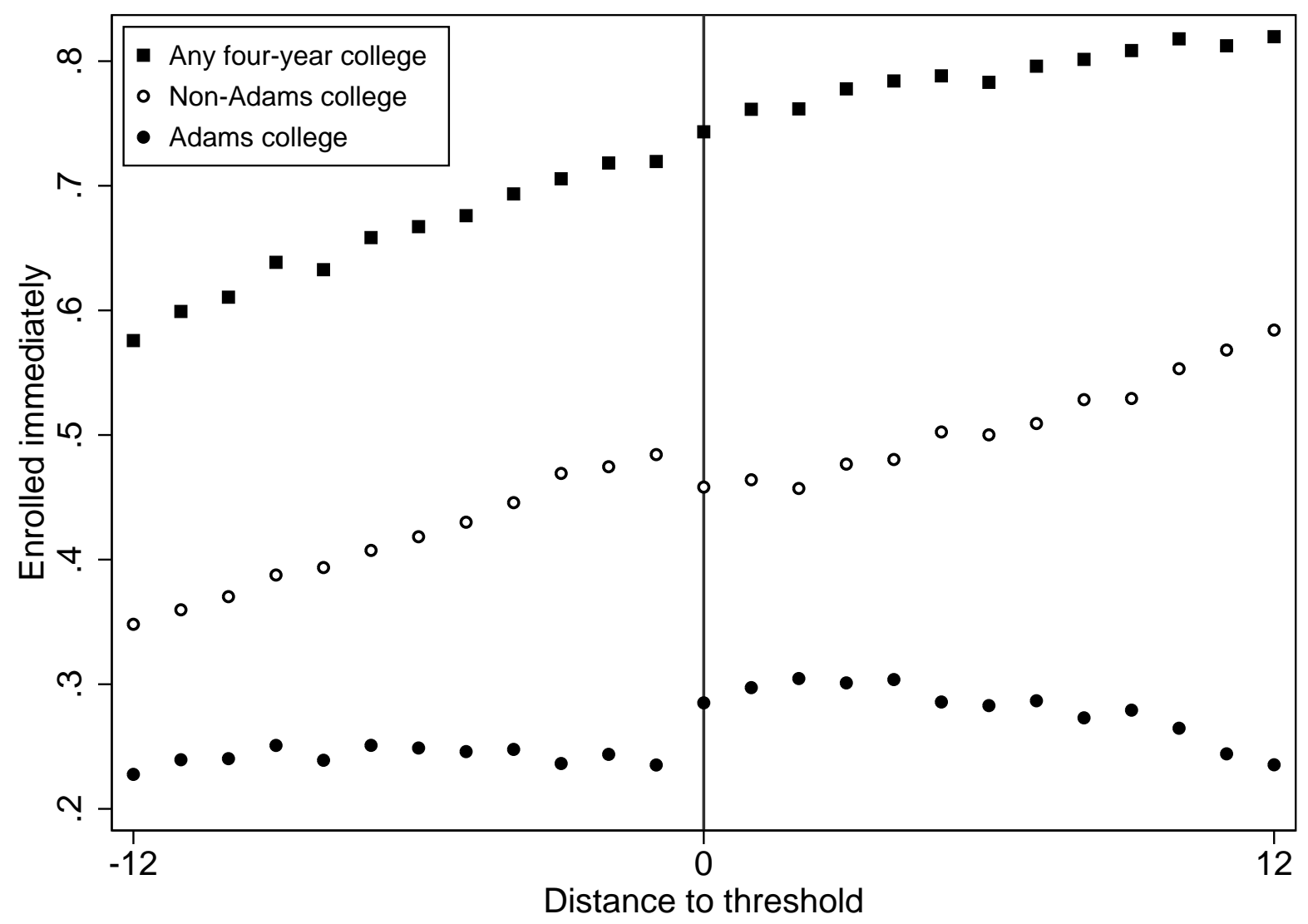

Notes: The above figure shows the fraction of students enrolling in four-year colleges immediately following high school graduation by each value of the running variable, for the high school classes of 2005-08. Adams colleges are Massachusetts public four-year colleges where the Adams Scholarship tuition waiver may be used. Non-Adams colleges are all other four-year colleges, both in-state and out of state. Calculations are based on National Student Clearinghouse data. 
Figure A.12: Graduation from Four-Year Colleges, Classes of 2005-08

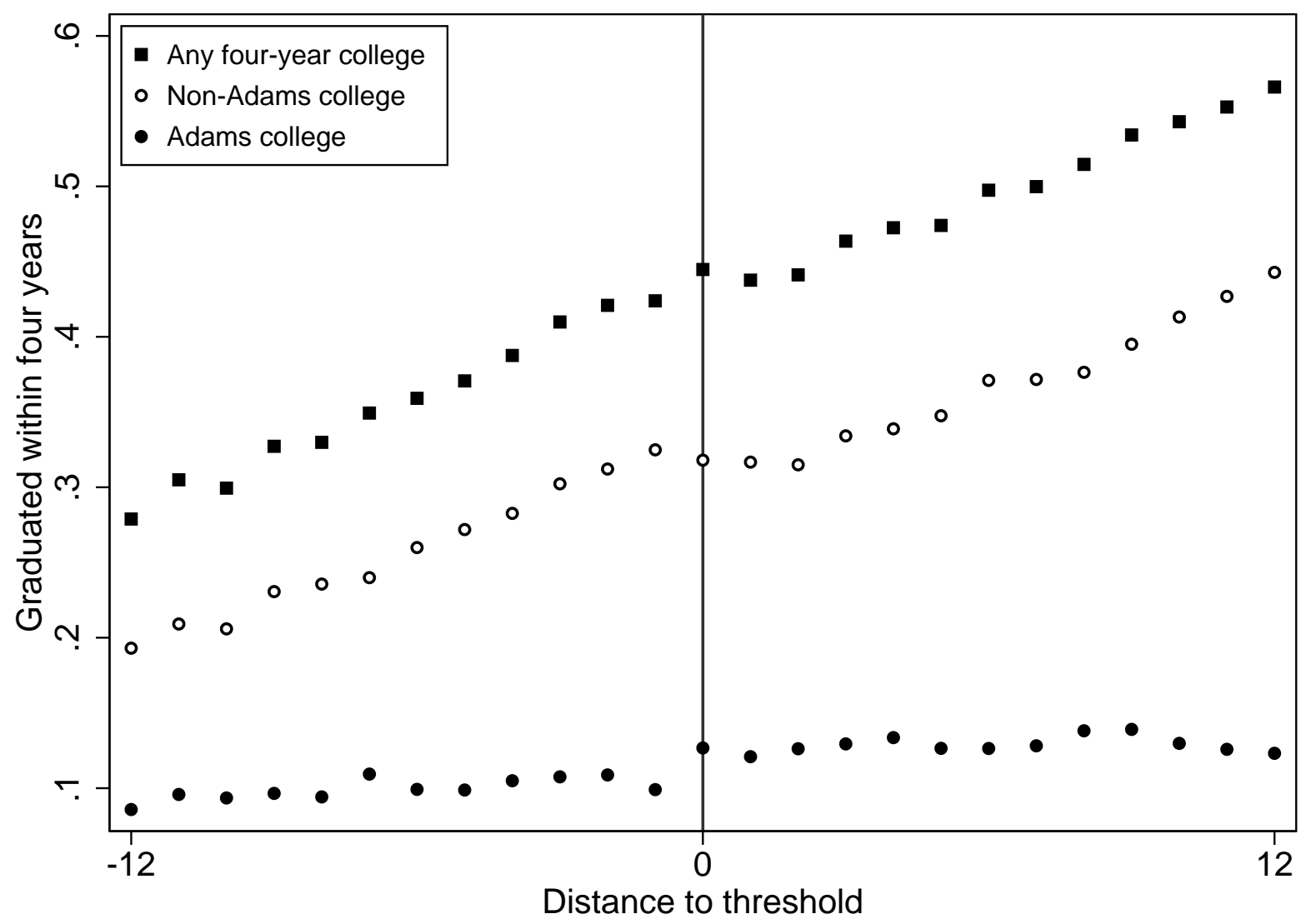

Notes: The above figure shows the fraction of students graduating from four-year colleges within six years of high school graduation by each value of the running variable, for the high school classes of 2005-08. Adams colleges are Massachusetts public four-year colleges where the Adams Scholarship tuition waiver may be used. Non-Adams colleges are all other four-year colleges, both in-state and out of state. Calculations are based on National Student Clearinghouse data. 
Table A.1: College Quality Measures, Selected Institutions

\begin{tabular}{|c|c|c|c|c|c|c|}
\hline & $\begin{array}{c}2004 \mathrm{MA} \\
\text { freshmen } \\
(1)\end{array}$ & $\begin{array}{c}\text { Four-year } \\
\text { grad. rate } \\
\text { (2) }\end{array}$ & $\begin{array}{c}\text { SAT math } \\
\text { score, p75 } \\
\text { (3) }\end{array}$ & $\begin{array}{c}\text { Instr. } \\
\text { spending } \\
(4)\end{array}$ & $\begin{array}{c}\text { College } \\
\text { quality } \\
\text { (5) }\end{array}$ & $\begin{array}{c}\text { Net } \\
\text { price } \\
(6)\end{array}$ \\
\hline \multicolumn{7}{|l|}{ (A) Adams colleges } \\
\hline U. Mass. Amherst & 2608 & .43 & 630 & 9.9 & .02 & 8.6 \\
\hline U. Mass. Dartmouth & 1078 & .26 & 580 & 5.3 & -.72 & 10.7 \\
\hline U. Mass. Lowell & 793 & .24 & 610 & 6.4 & -.58 & 7.6 \\
\hline U. Mass. Boston & 349 & .12 & 560 & 8.8 & -1.03 & 8.3 \\
\hline Bridgewater State & 959 & .23 & 560 & 3.7 & -.93 & 7.7 \\
\hline \multicolumn{7}{|l|}{ (B) Other colleges } \\
\hline Suffolk Univ. & 420 & .35 & 550 & 12.2 & -.53 & 23.3 \\
\hline Univ. of Rhode Island & 287 & .35 & 600 & 7.3 & -.38 & 19.4 \\
\hline Johnson and Wales Univ. & 436 & .42 & 590 & 7.2 & -.32 & 16.9 \\
\hline Univ. of Connecticut & 275 & .45 & 650 & 13.2 & .26 & 18.3 \\
\hline Merrimack College & 231 & .45 & 590 & 7.5 & -.22 & 15.6 \\
\hline Univ. of Vermont & 228 & .50 & 630 & 10.8 & .18 & 18.1 \\
\hline Univ. of New Hampshire & 502 & .54 & 620 & 8.9 & .17 & 19.7 \\
\hline Syracuse Univ. & 216 & .66 & 670 & 16.8 & .88 & 17.7 \\
\hline Boston Univ. & 587 & .62 & 690 & 32.5 & 1.33 & 17.2 \\
\hline Tufts Univ. & 186 & .84 & 740 & 29.1 & 1.96 & 15.1 \\
\hline Harvard Univ. & 124 & .86 & 790 & 107.8 & 4.35 & 12.3 \\
\hline
\end{tabular}

Notes: College characteristics are taken from IPEDS and are measured in the fall of 2004. Instructional spending and net price are measured in thousands of dollars. College quality is the standardized first principal component of each institution's four-year graduation rate, the 75th percentile SAT math score, and instructional expenditures per student, measured as of 2004. 


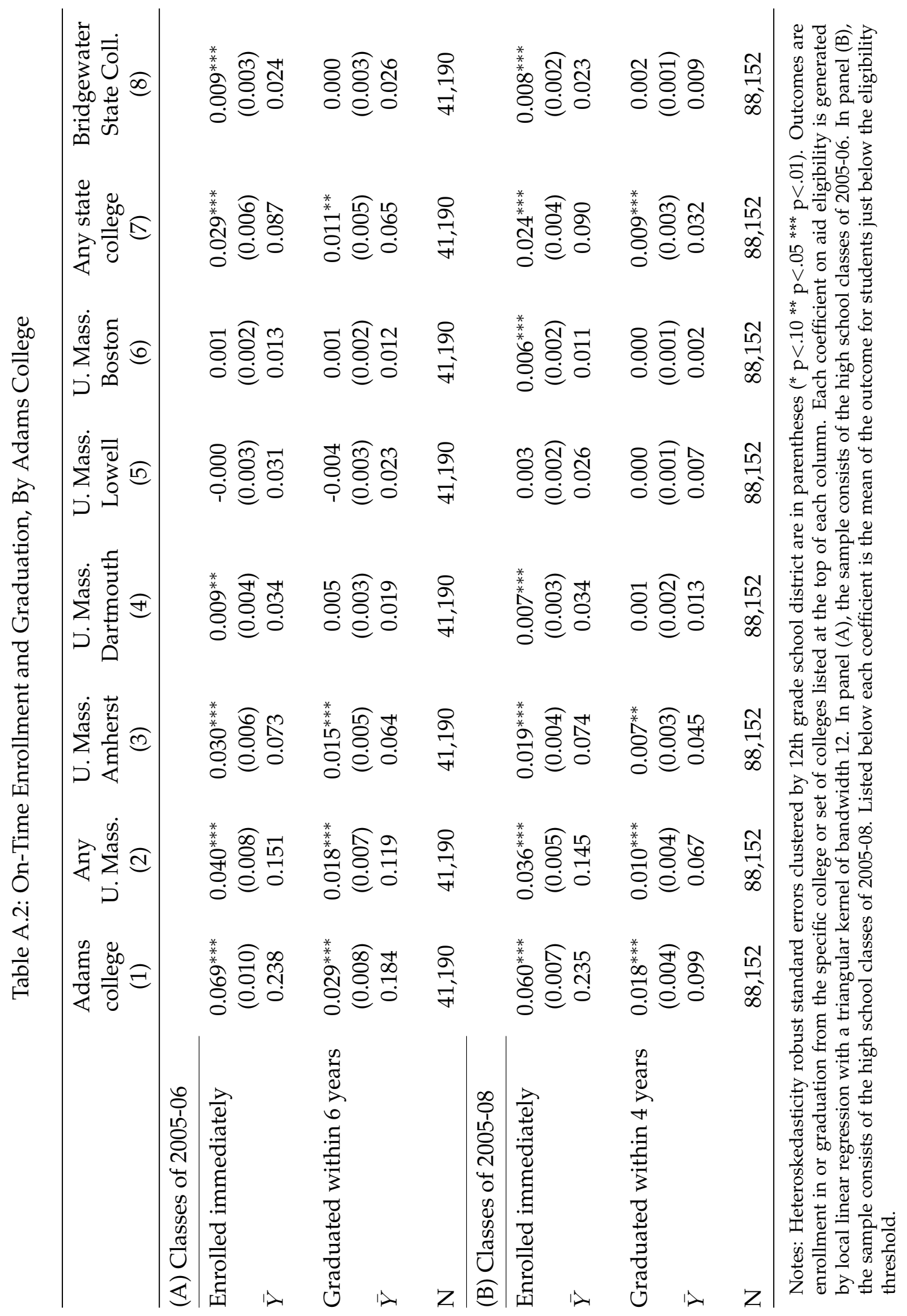


Table A.3: Robustness Checks

\begin{tabular}{|c|c|c|c|c|c|c|}
\hline & \multicolumn{3}{|c|}{ Classes of 2005-06 } & \multicolumn{3}{|c|}{ Classes of 2005-08 } \\
\hline & $\begin{array}{c}\text { Enrolled } \\
\text { immed., } \\
\text { Adams } \\
\text { college } \\
\quad(1)\end{array}$ & $\begin{array}{l}\text { On campus } \\
\text { in year } 4, \\
\text { four-year } \\
\text { college } \\
(2)\end{array}$ & $\begin{array}{l}\text { Graduated } \\
\text { within 6, } \\
\text { four-year } \\
\text { college } \\
\text { (3) }\end{array}$ & $\begin{array}{c}\text { Enrolled } \\
\text { immed., } \\
\text { Adams } \\
\text { college } \\
\quad(4)\end{array}$ & $\begin{array}{l}\text { On campus } \\
\text { in year } 4, \\
\text { four-year } \\
\text { college } \\
(5)\end{array}$ & $\begin{array}{l}\text { Graduated } \\
\text { within 4, } \\
\text { four-year } \\
\text { college } \\
\text { (6) }\end{array}$ \\
\hline \multicolumn{7}{|c|}{ (A) LLR, no controls } \\
\hline IK bandwidth & $\begin{array}{c}0.067^{* * *} \\
(0.009)\end{array}$ & $\begin{array}{c}-0.022^{* *} \\
(0.010)\end{array}$ & $\begin{array}{c}-0.023^{* *} \\
(0.009)\end{array}$ & $\begin{array}{c}0.060^{* * *} \\
(0.007)\end{array}$ & $\begin{array}{c}-0.017^{* *} \\
(0.007)\end{array}$ & $\begin{array}{l}-0.009 \\
(0.007)\end{array}$ \\
\hline $\mathrm{BW}$ & 14.3 & 10.2 & 10.3 & 11.3 & 9.5 & 9.4 \\
\hline $\mathrm{BW}=6$ & $\begin{array}{c}0.073^{* * *} \\
(0.014)\end{array}$ & $\begin{array}{l}-0.014 \\
(0.013)\end{array}$ & $\begin{array}{l}-0.013 \\
(0.014)\end{array}$ & $\begin{array}{c}0.056^{* * *} \\
(0.009)\end{array}$ & $\begin{array}{l}-0.016^{*} \\
(0.010)\end{array}$ & $\begin{array}{c}-0.002 \\
(0.010)\end{array}$ \\
\hline $\mathrm{BW}=9$ & $\begin{array}{c}0.072^{* * *} \\
(0.011)\end{array}$ & $\begin{array}{c}-0.020^{* *} \\
(0.010)\end{array}$ & $\begin{array}{c}-0.019^{*} \\
(0.010)\end{array}$ & $\begin{array}{c}0.059^{* * *} \\
(0.007)\end{array}$ & $\begin{array}{c}-0.017^{* *} \\
(0.007)\end{array}$ & $\begin{array}{l}-0.008 \\
(0.008)\end{array}$ \\
\hline $\mathrm{BW}=12$ & $\begin{array}{c}0.069^{* * *} \\
(0.010)\end{array}$ & $\begin{array}{c}-0.023^{* * *} \\
(0.009)\end{array}$ & $\begin{array}{c}-0.025^{* * *} \\
(0.009)\end{array}$ & $\begin{array}{c}0.060^{* * *} \\
(0.007)\end{array}$ & $\begin{array}{c}-0.017^{* * *} \\
(0.006)\end{array}$ & $\begin{array}{l}-0.010 \\
(0.007)\end{array}$ \\
\hline $\mathrm{BW}=15$ & $\begin{array}{c}0.067^{* * *} \\
(0.009)\end{array}$ & $\begin{array}{c}-0.021^{* *} \\
(0.008)\end{array}$ & $\begin{array}{c}-0.025^{* * *} \\
(0.008)\end{array}$ & $\begin{array}{c}0.059^{* * *} \\
(0.006)\end{array}$ & $\begin{array}{c}-0.016^{* * *} \\
(0.006)\end{array}$ & $\begin{array}{c}-0.012^{* *} \\
(0.006)\end{array}$ \\
\hline $\mathrm{BW}=18$ & $\begin{array}{c}0.066^{* * *} \\
(0.009)\end{array}$ & $\begin{array}{c}-0.018^{* *} \\
(0.008)\end{array}$ & $\begin{array}{c}-0.024^{* * *} \\
(0.008)\end{array}$ & $\begin{array}{c}0.059^{* * *} \\
(0.006)\end{array}$ & $\begin{array}{c}-0.015^{* * *} \\
(0.005)\end{array}$ & $\begin{array}{c}-0.012^{* *} \\
(0.005)\end{array}$ \\
\hline \multicolumn{7}{|l|}{ (B) $\mathrm{LLR}, \mathrm{BW}=12$} \\
\hline District $^{*}$ class FE & $\begin{array}{c}0.065^{* * *} \\
(0.010)\end{array}$ & $\begin{array}{c}-0.021^{* *} \\
(0.008)\end{array}$ & $\begin{array}{c}-0.020^{* *} \\
(0.009)\end{array}$ & $\begin{array}{c}0.053^{* * *} \\
(0.006)\end{array}$ & $\begin{array}{c}-0.015^{* *} \\
(0.006)\end{array}$ & $\begin{array}{l}-0.003 \\
(0.006)\end{array}$ \\
\hline Demographics & $\begin{array}{c}0.069^{* * *} \\
(0.010)\end{array}$ & $\begin{array}{c}-0.022^{* *} \\
(0.009)\end{array}$ & $\begin{array}{c}-0.022^{* *} \\
(0.009)\end{array}$ & $\begin{array}{c}0.060^{* * *} \\
(0.007)\end{array}$ & $\begin{array}{c}-0.018^{* * *} \\
(0.006)\end{array}$ & $\begin{array}{l}-0.011^{*} \\
(0.007)\end{array}$ \\
\hline Donut hole & $\begin{array}{c}0.079^{* * *} \\
(0.011)\end{array}$ & $\begin{array}{c}-0.030^{* * *} \\
(0.011)\end{array}$ & $\begin{array}{c}-0.036^{* * *} \\
(0.011)\end{array}$ & $\begin{array}{c}0.071^{* * *} \\
(0.008)\end{array}$ & $\begin{array}{c}-0.025^{* * *} \\
(0.007)\end{array}$ & $\begin{array}{c}-0.020^{* * *} \\
(0.007)\end{array}$ \\
\hline \multicolumn{7}{|l|}{ (C) Parametric } \\
\hline Quadratic & $\begin{array}{c}0.063^{* * *} \\
(0.009)\end{array}$ & $\begin{array}{c}-0.028^{* * *} \\
(0.008)\end{array}$ & $\begin{array}{c}-0.029^{* * *} \\
(0.008)\end{array}$ & $\begin{array}{c}0.051^{* * *} \\
(0.006)\end{array}$ & $\begin{array}{c}-0.026^{* * *} \\
(0.006)\end{array}$ & $\begin{array}{c}-0.023^{* * *} \\
(0.006)\end{array}$ \\
\hline Cubic & $\begin{array}{c}0.068^{* * *} \\
(0.011)\end{array}$ & $\begin{array}{c}-0.028^{* * *} \\
(0.010)\end{array}$ & $\begin{array}{c}-0.035^{* * *} \\
(0.010)\end{array}$ & $\begin{array}{c}0.061^{* * *} \\
(0.007)\end{array}$ & $\begin{array}{c}-0.019^{* * *} \\
(0.007)\end{array}$ & $\begin{array}{c}-0.014^{* *} \\
(0.007)\end{array}$ \\
\hline Quartic & $\begin{array}{c}0.063^{* * *} \\
(0.012)\end{array}$ & $\begin{array}{c}-0.029^{* *} \\
(0.012)\end{array}$ & $\begin{array}{c}-0.029^{* * *} \\
(0.011)\end{array}$ & $\begin{array}{c}0.057^{* * *} \\
(0.008)\end{array}$ & $\begin{array}{c}-0.015^{*} \\
(0.008)\end{array}$ & $\begin{array}{l}-0.004 \\
(0.009)\end{array}$ \\
\hline
\end{tabular}

Notes: Heteroskedasticity robust standard errors clustered by 12 th grade school district are in parentheses $\left({ }^{*} \mathrm{p}<.10\right.$ ${ }^{* *} \mathrm{p}<.05^{* * *} \mathrm{p}<.01$ ). In panel $\mathrm{A}$, each coefficient on aid eligibility is generated by local linear regression with a triangular kernel of the listed bandwidth. Each row in panel B replicates the panel A specification using a bandwidth of 12, with modifications. The first row adds school district by class fixed effects. The second row adds controls for gender, race, low-income status, limited English proficiency and special education status. The third row excludes observations on the eligibility threshold. Panel $C$ fits quadratic, cubic and quadratic functions on either side of the threshold, using the entire sample and a rectangular kernel. The samples consists of the high school classes of 2005-06 and 2005-08. 